\title{
Equilibrium Analysis, Banking and Financial Instability ${ }^{*}$
}

\section{by}

\author{
Dimitrios P. Tsomocos*
}

First version: January 2000

Current version: December 2001

\footnotetext{
*CDimitrios P.Tsomocos

- Bank of England and International Financial Stability Programme. The views expressed are those of the author and do not necessarily reflect those of either the Bank of England or the International Financial Stability Programme of L.S.E.

I am grateful to Stelios Leonidou, Milan Kutmutia for excellent research assistance, W. Buiter, E. Catarineu-Rabell, F. Heinz, C. Goodhart, R. Repullo, H.-S. Shin, M. Shubik, seminar participants at the Bank of England, $56^{\text {th }}$ ESEM, Economics University of Athens, L.S.E., Indian Statistical Institute, University of Athens, University of Frankfurt, University of Oxford, V CSAET, Yale University and especially Pradeep Dubey, Glenn Hoggarth and Geoffrey Wood for helpful comments and remarks. However, all remaining errors are mine. 


\begin{abstract}
This paper first extends the canonical General Equilibrium with Incomplete Markets (GEI) model with money and default to allow for competitive banking and financial instability. Second, it introduces capital requirements for the banking sector to assess the short and medium term macroeconomic consequences of the proposed New Basel Accord. The model is rich enough to include heterogeneous households and banks, multiple commodities and credit markets and endogenous default. Agent optimisation, rational expectations and market clearing are maintained throughout. Because of the important role that money plays, Monetary Equilibria with Commercial Banks and Default (MECBD) exist only if there are sufficient gains-to-trade (i.e., the ratio of outside to inside money is less than the gains-to-trade available at every state of the world at the initial allocation). Thus, existence of MECBD guarantees the positive value of money in finite horizon and allows for positive default levels in equilibrium. It also characterises financial instability as an equilibrium phenomenon.
\end{abstract}

A non-trivial quantity theory of money is derived in which both prices and quantities are allowed to change and the term structure of interest rates incorporates both the 'expectations' and the 'liquidity preference' hypothesis. The 'classical dichotomy' typically fails to hold and the interaction of the nominal and the real sector of the economy determines interest rates. Thus, monetary, fiscal and regulatory policies necessarily generate real effects. Non-neutrality relies upon the real and nominal determinacy of MECBD, whenever at least one nominal interest rate is positive. As a result of the liquidity constraints the linear pricing rule of assets fails to hold.

A definition of financial instability is proposed. Financial instability occurs when aggregate profitability of the banking sector declines and the number of defaults in the household and the banking sectors increase. Thus, $a$ financially unstable MECBD requires financial vulnerability in the banking sector and liquidity shortages in the private.

A version of the liquidity trap holds where banks engage in large asset trades without changing interest rates in the households' credit markets, no matter how expansionary monetary policy is. The Diamond-Dybvig (1983) result is a special case of MECBD in which banks are homogeneous and financial contagion due to default is maximal. Finally, because of the presence of capital requirements for banks, a trade off exists between regulatory policy and efficiency. It is also shown that under certain restrictions and binding capital requirements, MECBD are constrained inefficient. Thus, adjustment of capital requirements may generate efficiency gains. Competitive equilibrium analysis simplifies many of the complications of finite-players games that address the same issues

The model provides a useful analytical device for policy analysis of situations in which crisis prevention and management become necessary to reduce the risks and costs of financial instability.

Keywords: Financial instability, competitive banking, capital requirements, Basel accord, regulation, incomplete markets, default, non-neutrality, Gains-to-Trade.

JEL Classification: D52, E4, E5, G1, G2. 


\section{Contents}

\section{Introduction}

2. The model

2.1 The economy

2.2 Central Bank, Government and the Regulator

2.3 The Market Structure and the Transmission Mechanism

2.4 The Time Structure of Markets

2.5 Asset Markets

2.6 Money and Credit Markets

2.7 Default

2.8 Capital Requirements

2.9 The commodity Markets

2.10 Stocks, Flows and Liquidity Constraints

2.11 Commercial Banks

2.12 Interbank Credit Market

3. The Budget set

3.1 Investors/Households

3.2 Commercial Banks

\section{Equilibrium}

5. Money Demand, Quantity Theory of Money and the Term Structure of Interest Rates

6. Asset Pricing

7. The Orderly Function of Markets: Existence

8. Financial Instability, Contagion and Systemic Risk

8.1 Financial Instability: Concepts, Definitions

8.2 Liquidity Trap

8.3 Bank Runs

8.4 Constrained Inefficiency

9. Determinacy and Non-neutrality of Money and Regulatory Policy

10. MECBD vs. GEI and GE

10.1 The Optimum Quantity of Money

\section{Concluding Remarks}

\section{References}

Appendix 


\section{Introduction}

Recent financial crises in Texas banking during the 1980's, in Scandinavia and the U.K. in the early 90's, in Mexico in 1995, East Asia in 1997, Russia in 1998, the near-collapse of LTCM and Japan has renewed the interest in studying financial instability. Its origins, propagation mechanisms, macroeconomic consequences and ultimately its containment are some of the issues that have recently attracted attention. A clear understanding of financially unstable regimes is a prerequisite for crisis management and prevention as well as prudential regulation. International organisations have proposed and legislated measures to ensure financial stability in the global markets and to reduce its systemic externality. Pre-eminent among them the BIS proposed New Accord [6] for capital requirements in February 2001.

The difficulty of analysing financial instability lies in the fact that most of the crises manifest themselves in a seemingly unique manner and almost always require different policies for their tackling. A potpouri of models, primarily game-theoretic in nature, have been introduced to address financial instability. After the seminal papers of Bryant [11] and Diamond-Dybvig [19], a multitude of papers [2], [42] $]^{1}$, have attempted to rationalise bank-runs and panics based on some type of coordination failure. Most of them depend on asymmetric information and some type of moral hazard friction. More recently, S. Morris and H-S. Shin [48] suggested an argument stemming from coordination failure and switching strategies that select a unique equilibrium and offers an explanation for some of the recent currency crises. In addition, various empirical papers and surveys summarise the characteristics of financial crises and systemic risk. A by no means exhaustive list includes [29], [40], [47].

Some additional minimum structural characteristics should be present in any model attempting to capture fundamental aspects of financial instability. First, it should be multiperiod, with aggregate uncertainty and agent heterogeneity. Different actions and policy recommendations are necessary for crisis resolution depending on the structure of economic uncertainty and the impact on various economic sectors. Second, money and liquidity constraints should be explicit, since financial crises evolve from the nominal sector and subsequently spread to the real economy. Third, since the performance of banks is critical for the study of financial instability a banking sector well integrated in the model is indispensable to any modelling attempt. Finally, the regulatory framework should be clearly defined for policy and sensitivity analysis of various regulatory regimes.

This paper follows a slightly novel approach in modelling financial instability. Almost always a common feature of most crises is increased default and lower profitability in the banking sector. Empirical studies [16], [29], [40] show that the amount of non-performing loans increases precipitously before and during a crisis, and bank profitability falls. A definition of financial instability that depends on increased default by the household and banking sector and reduced bank profitability is suggested. The conventional definitions follow as limit cases of this more "gradual" definition. It allows for analysis of financial stability issues as a continuum of possible contingencies whereas standard definitions usually consider only polar situations, which are tantamount to financial crises. Consequently, analysing financial instability in the continuum implies that crisis prevention/management policies may be readily applied before an actual crisis occurs.

The canonical GEI model with money and default by Dubey and Geanakoplos [21] and Dubey, Geanakoplos and Shubik [22] is extended to incorporate a competitive banking sector. Commercial banks are heterogeneous and maximise their expected profits. They are owned by their shareholders

\footnotetext{
${ }^{1}$ For an excellent survey of these models see the textbook of X. Freixas and J-C Rochet [24], where most of them are presented. Also, see [1] where the recent contributions of F. Allen and D. Gale are presented.
} 
who have bought shares (as in Shubik and Tsomocos [55]). This modelling approach allows for a variety of financial institutions, not just commercial banks. The key distinction between financial intermediaries and the household/investor sectors is while the former maximise profits the latter maximise utility of consumption. Heterogeneous banks differ among themselves with respect to initial capital endowments, risk preferences (i.e., coefficients of risk aversion) and assessments of future scenarios (i.e., subjective probabilities). The modelling of the banking sector is akin to Tobin [49]: banks borrow from investors/households and from the Central Bank via the interbank credit market $^{2}$ and extend credit to them via the consumer credit markets. They also hold a diversified portfolio of securities.

The remaining characteristics of the model are consistent with the standard GEI and its extension to include money and default. ${ }^{3}$ The analysis of the proposed New Basel Accord needs the imposition of state dependent capital requirements that may or may not depend on other macroeconomic variables such as output and default. It extends over two periods and uncertainty is resolved in the second. Assets are traded in the first period and payoff in the second. An equity market for ownership shares of commercial banks meets in the first period. The Central Bank interacts with commercial banks via the interbank market in the first period and loan settlement occurs in the second. One intraperiod consumer credit market per state and one interperiod consumer credit market, in which commercial banks extend credit to households, exist. Thus, commercial banks can be viewed as creators of "money" a la Tobin [58]. Commodity markets meet in each state and cash-in-advance is needed for all market transactions. Both households and banks are allowed to default on their financial obligations, namely, asset deliveries and loan repayments. They are penalised proportionally to their size of default by subtracting a linear term from their respective objective function.

The closest methodological precursor to this model is the work of Martin Shubik [51], [53], [54] who introduced a Central Bank with exogenously specified stocks of money, and cash-in-advance constraints in a strategic market game. ${ }^{4}$ Shubik [53] also emphasised the virtues of explicitly modelling each transaction. Grandmont [30], [31], [32], [33] also introduced a banking sector into general equilibrium with overlapping generations and he pointed out the inefficiency of trade with money. The commercial banking sector of this model follows closely Shubik and Tsomocos [55], who used, however, gold-backed money and modelled a mutual bank with fractional reserves. Finally, the modelling of money and default in an incomplete markets framework is akin to the models developed by Dubey and Geanakoplos [20], [21] and Dubey, Geanakoplos and Shubik [22]. However, [20] is a one period model with money and default, [21] includes incomplete asset markets and money, and [22] has incomplete asset markets, default and no money. None of the previous papers combines all three ingredients, incorporates a competitive commercial banking sector, and focuses on financial instability. In addition, Dubey and Geanakoplos [20] introduced the gains-totrade hypothesis and private monetary endowments that guarantee positive value of money in finite horizon as well as positive interest rates. ${ }^{5}$ Default is modelled as in Shubik [53] and Shubik and Wilson [55], namely by subtracting a linear term from the objective function of the defaulter proportional to the debt outstanding.

In section 2, the model is presented and the roles of the Central Bank, government, the regulator and commercial banks are analysed. Also, the time and market structure is described. Sections 3-4, formally describe the budget sets of the households, the commercial banks and Monetary

\footnotetext{
${ }^{2}$ The repo and the interbank market are collapsed into one, since my focus is on contagion and financial fragility and not on monetary policy.

3 Excellent introductions to this methodology are provided in [22], [46 ].

4 The cash-in-advance constraint can be traced at least as far as back as Clower [15 ], [16], and has been used extensively by Lucas [43],[44],[45].

5 Alternatively, one needs positive default as in Shubik and Tsomocos [55] and Shubik and Wilson [56].
} 
Equilibrium with Commercial Banks and Default is defined. Section 5 derives the quantity theory of money proposition in which both prices and quantities adjust in response to policy changes. This result differs from Lucas [43], [44], [45], because he postulated a 'sell-all model' in which every agent sells everything he owns in every period. So, the number of transactions is fixed by definition. In this model agents transact only if they wish to do so. Moreover, in order to make his model more tractable, he relies on the representative agent hypothesis. In addition, the term structure of interest rates is specified in which the expectations and the liquidity preference hypothesis are accommodated and default influences its shape. Section 6 shows that the linear asset pricing rule fails to hold in equilibrium because of the 'liquidity cost' of transactions due to positive interest rates. Positive interest rates induce a 'price wedge' between the selling and buying price of an asset equal to $(1+r)$ for example, provided that $r>0$.

Section 7 establishes existence of Monetary Equilibria with Commercial Banks and Default provided that the necessary gains-to-trade are present in the initial allocation. Put differently, the ratio of the aggregate monetary endowment of households and initial capital of commercial banks to the Central Bank money injected to the economy in the interbank market should be less than the gains-to-trade that agents can reap through market transactions. Indeed, the ratio of these monetary aggregates is what determines the term structure of interest rates equation that is derived in section 5 . Besides resolving the well-known 'Hahn Paradox' of supporting a positive value of fiat money in finite horison, MECBD manifest two seemingly paradoxical properties. First, default appears endogenously as a choice of optimising agents and is compatible with equilibrium. Second, financially unstable regimes are also compatible with the orderly function of the markets. The importance of this property is that financial vulnerability presents itself as an externality to the financial system with real effects. Consequently, it can be a parameter of policy making and by using specific policy instruments it can successfully be dealt with.

A definition of financial instability is proposed in section 8 and the properties of MECBD are examined. In particular, a version of the Keynesian liquidity trap holds in which commodity prices stay bounded whereas asset trades tend to infinity whenever monetary policy is loosening. Moreover, this situation corresponds to a financially unstable equilibrium. The seminal Diamond-Dybvig [19] result of bank runs manifests itself in the model under certain assumptions, namely homogeneity of commercial banks. Theorem 2 shows that MECBD are constrained inefficient provided that there is no default and capital requirements are binding.

Finally, in sections 9-10 the issues of determinacy, non-neutrality and the relationship among MECBD, GEI and GE are discussed. It is shown that monetary, fiscal and regulatory policy changes are non-neutral only when interest rates are positive and the policy variables change disproportionally. In turn, this property is ultimately connected with real and nominal determinacy of MECBD. Consequently, policy changes that affect the nominal sector of the economy necessarily generate real effects. Finally, when interest rates are zero then MECBD and GEI coincide and, in addition when the asset span equals the number of future states of the world the complete markets theorem obtains.

All the proofs of the theorems, propositions and corollaries are relegated to the appendix.

\section{The Model}

\subsection{The Economy}

Consider the canonical general equilibrium with incomplete markets model in which time extends over two time periods. The first period consists of one state whereas the second period consists of $\mathrm{S}$ 
possible states. Households/investors and commercial banks transact maximising their respective objective functions whereas the consolidated government/central bank and the regulator are modelled as "strategic dummies". Households participate in the trade of commodities, assets, consumer loans and shares of commercial banks. Commercial banks lend to the consumer credit markets and admit deposits. Also, they borrow and lend in the interbank credit market. Finally, they invest in the asset market and auction their shares of ownership in the equity market. The consolidated government/central bank operates in the interbank credit market via OMO's ${ }^{6}$ and conducts fiscal policy intervening in the commodity markets and through money financed fiscal transfers. ${ }^{7}$ The regulator fixes the bankruptcy code for households and commercial banks exogenously and sets the capital-adequacy requirements for the commercial banks.

Formally, the notation that will be used henceforth is as follows:

t $0 \mathrm{~T}=\{0,1\}=$ time periods,

s $0 \mathrm{~S}=\{1, \ldots, \mathrm{S}\}=$ set of states at $\mathrm{t}=1$,

$\mathrm{S}^{*}=\{0\} \cup \mathrm{S}=$ set of all states,

$\mathrm{h} \in \mathrm{H}=\{1, \ldots, \mathrm{H}\}=$ set of economic agents (households/investors),

$\mathrm{b} \in \mathrm{B}=\{1, \ldots, \mathrm{B}\}=$ set of commercial banks,

$1 \in \mathrm{L}=\{1, \ldots, \mathrm{L}\}=$ set of commodities,

$R_{+}^{L} \times R_{+}^{S L}=$ commodity space indexed by $\{0, \ldots \mathrm{S}\} \times\{1, \ldots \mathrm{L}\}$,

$e^{h} \in R_{+}^{L} \times R_{+}^{S L}=$ endowments of households ${ }^{8}$,

$e^{b} \in R_{+}^{S^{*}}=$ capital endowments of commercial banks.

Investors trade in assets to bet or to hedge. The speculative motive is incorporated in their utility functions by assigning different subjective probability assessments over all the future states of the world and the hedging motive by assuming that they maximise the expected utility of consumption rather than expected consumption per se.

$u^{h}: R_{+}^{L} \times R_{+}^{S L} \rightarrow R=$ utility function of agent $\mathrm{h} \in \mathrm{H}$,

$\chi_{s l}^{h} \equiv$ consumption of commodity $l$ in state $s$ by $h \in H$.

The standard assumptions hold:

(A1) $\forall s \in S^{*}$ and $l \in \mathrm{L}, \sum_{h \in H} e_{s l}^{h}>0$,

(i.e., every commodity is present in the economy.)

\footnotetext{
${ }^{6}$ Alternatively, it sets the interbank interest rate and provides liquidity for interbank reserves as is usually the current Central Bank practise.

${ }^{7}$ In [28], we allow for taxation and foreign exchange intervention.

${ }^{8}$ In section 2.6 , monetary endowments will be allowed.
} 
(A2) $\forall s \in S^{*}$ and $h(b) \in H(B), \quad e_{s l}^{h}>0\left(e_{s}^{b}>0\right)$ for some $l \in L\left(s \in S^{*}\right)$,

(i.e., no household (commercial bank) has the null endowment of commodities (capital) in any state of the world.)

(A3) Let $A$ be the maximum amount of any commodity $s l$ that exists and let 1 denote the unit vector in $R^{S L x L}$. Then $\exists Q>0 \rightarrow u^{h}(0, \ldots Q, \ldots 0)>u^{h}(\boldsymbol{A 1})$ for $Q$ in an ordinary component (i.e., strict monotonicity in every component). ${ }^{9}$ Also, continuity and concavity are assumed.

The money supply expansion mechanism of the economy highlights the importance of introducing multiple banks with active choice sets. Regulatory intervention in the financial system occurs primarily through the banking industry (e.g., capital-adequacy ratios etc). It is evident that the liquidity of the monetary economy as well as the equilibrium outcomes are affected by the risk profiles of commercial banks. Finally, the heterogeneity of banks is a crucial ingredient of analysing systemic effects of exogenous shocks occurring in a continuum of possible outcomes. Therefore, I will address the issue of bank heterogeneity by letting banks have different initial monetary endowments and utility functions of profits. Finally, concavity precipitates active behaviour.

$u^{b}: R_{+}^{S^{*}} \rightarrow R=$ utility function of bank $\mathrm{b}$

$\pi_{s}^{b}=$ monetary holdings of $\mathrm{b}$ at $s \in S^{*}$.

Two straightforward assumptions are imposed.

(A4) $\forall s \in S^{*}$ and $b \in B, e_{s}^{b}>0$,

(i.e. no bank has the null endowment at any state.)

(A5) Let $A_{m}$ be the maximum amount of money present in the economy and let 1 denote the unit vector in $R^{s^{*}}$. Then $\exists Q>0 \ni u^{b}(0 \ldots, Q, \ldots 0)>u^{b}\left(A_{m} 1\right)$

for $Q$ in an arbitrary component (i.e., strict monotonicity in every component). ${ }^{10}$ Also continuity and concavity are assumed.

\subsection{Government, Central Bank and the Regulator}

There is a government sector, which has the capacity to act on markets through, for example, the Central Bank or treasury or Federal Reserve. A regulatory agency legislates the bankruptcy code of the economy and fixes the capital adequacy requirements. Both of these institutions' actions are exogenously specified and the consequences of their choices are analysed.

The government sector (i.e., including the Central Bank) buys commodities implements money financed fiscal transfers and conducts open market operations in the interbank credit market. Government purchases of commodities as part of fiscal policy. ${ }^{11}$

\footnotetext{
${ }^{9}$ The results remain unaltered if, instead of the previous condition, we assume smoothness of $\mathrm{u}^{\mathrm{h}}$.

${ }^{10}$ The results remain unaltered if, instead of the previous condition, we assume smoothness of $u^{\mathrm{b}}$.

${ }^{11}$ One can extend the choice set of government to include taxation. See [28] for details.
} 
Formally, the following vector gives the government and Central Bank's actions

$$
\left(M^{G}, \mu^{G}, m^{G}, b^{G}\right) \equiv\left(M^{G} ; \mu^{G},\left(m_{h s}^{G}\right)_{h \in H \cup B, s \in S^{*}} ;\left(b_{s l}^{G}\right)_{s \in S^{*}, l \in L}\right)
$$

where,

and

$M^{G}=$ OMOs on behalf of the government/central bank,

$\mu^{G}=$ bond sales by the government/Central Bank,

$m^{G}=$ money financed fiscal transfers to households and Emergency Liquidity Assistance to commercial banks,

Note that the government it is not required to spend less than it borrows; the existence of equilibrium is compatible with the Central Bank printing money to finance its expenditures. All the results hold for both cases, (i.e., with or without money financing) except where otherwise stated. ${ }^{12}$

Similarly, the following vector gives the regulator's actions

$$
(\kappa, \lambda, \omega) \equiv\left(\left(_{s}^{b}\right)_{b \in B, s \in S} ;\left(\lambda_{s}^{h}\right)_{h \in H \cup B, s \in S} ;\left(\omega_{i j}^{b}\right)_{b \in B, i \in S, j \in J}\right) \text { where, }
$$

$\kappa^{\prime} \mathrm{s}$ are the time varying capital-adequacy ratios prevailing in the commercial banking sector, $\lambda$ 's are the bankruptcy penalties imposed upon the parties breaking their contractual obligations and $\omega$ 's are the time-varying risk weights of bank assets that apply for the calculation of the capital requirements. ${ }^{13}$ The analysis of default and bankruptcy is conducted in section 2.7 . and of the capital requirements in section 2.8 .

\subsection{The Market Structure and the Transmission Mechanism}

The model consists of markets for commodities, marketed assets, consumer credit, interbank credit and banks' equity. There exist $L S^{*}$ commodity markets that meet at $t=0$ and $t=1$. The financial side of the economy contains $J$ secondary asset markets and one short-term credit market per state. In addition, there exists one long-term credit market. Shares of commercial banks are traded in the primary equity market. The structure of the markets is summarised in figure 2 .

The structure of the model shown in figure 2 is similar to the market structure of Geanakoplos and Tsomocos [23]. There are commodity markets for each traded commodity and credit markets in which the investors/households acquires its short and long term financing. As in the incomplete markets literature, assets can be traded today and deliver a promised payoff in the future. If the respective payoff consists of both physical commodities and money the asset is called a real asset; if it consists of only money it is called a financial asset. The most important financial asset is the socalled riskless asset ${ }^{14}$ whose promised payoff is 1 across all future states. The asset market captures the functions of the secondary market since it does not include initial public offerings of assets. Finally, market incompleteness ('missing financial markets') is captured by assuming that there are

\footnotetext{
${ }^{12}$ However, at the end of $t=1$ the government observes its budget constraints. As I discuss in section 9, money nonneutrality depends on the positive interest rate and not exclusively on government financing.

${ }^{13}$ Time varying risk weights are consistent with the proposed new Basel Accord.

${ }^{14}$ Loans are not riskless assets since borrowers can default on them.
} 
fewer assets than future states of the world. No attempt is made to derive market incompleteness endogenously; this is beyond the scope of this paper.

The banking sector interacts with the Central Bank via the interbank credit market and supplies credit to the investors/shareholders via the credit markets. Monetary policy is conducted in the interbank market with open market operations and is affected by interbank lending. Commercial banks hold a diversified portfolio of securities through investments in the asset market. Thus, their assets consist of loans and their positions in the asset market. In addition to their initial capital endowment, commercial banks issue equity, which may be acquired by the investors. The model is closed by distributing the profits of the banking sector (if any) back to the shareholders. 
FIGURE 1

MARKET STRUCTURE OF THE MODEL

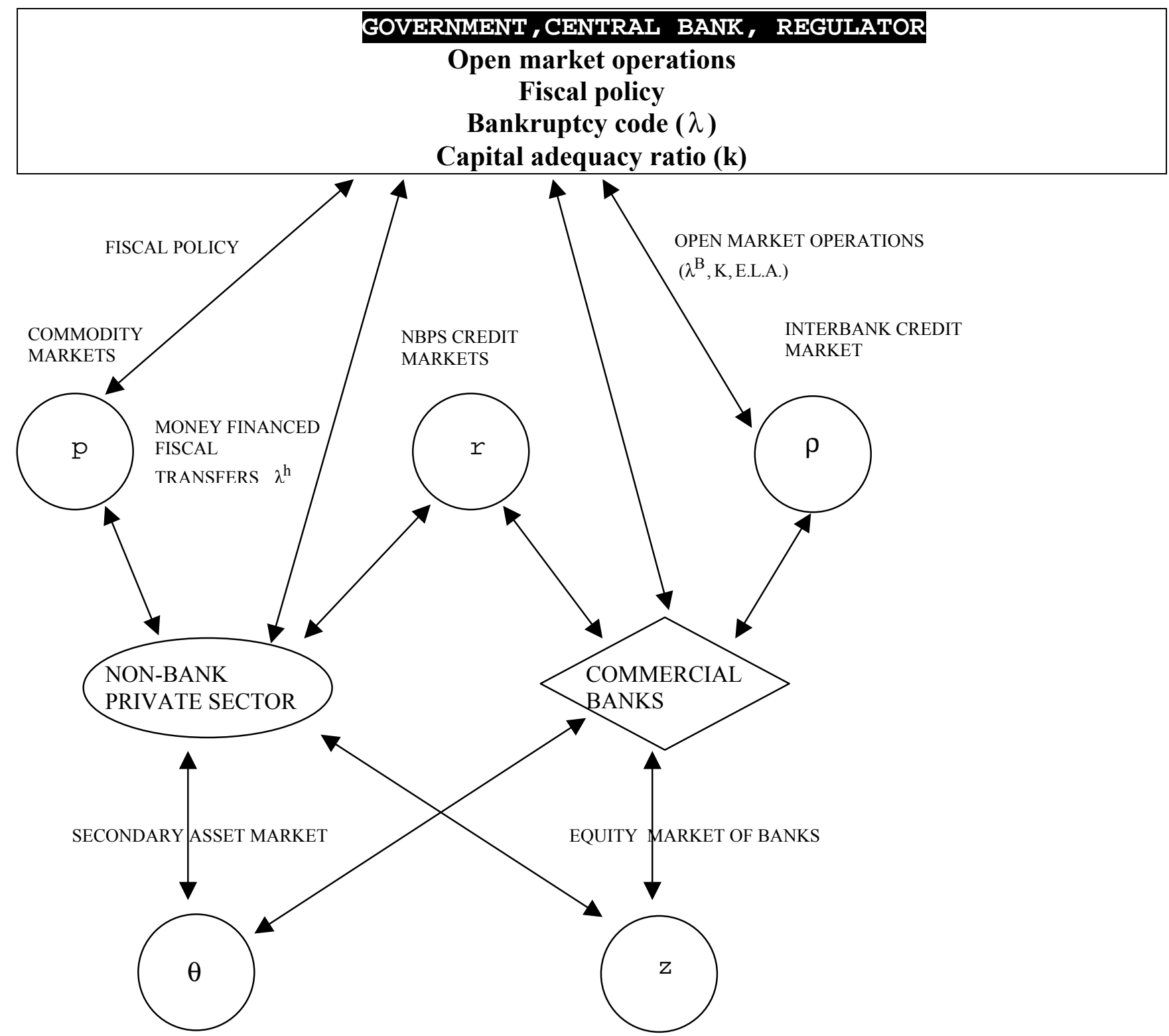

Where,

$\mathrm{P}=$ Commodity prices

$\mathrm{r}=$ Credit market interest rate

$\rho \quad=$ Interbank interest rate

$\theta \quad=$ Asset prices

$\mathrm{z} \quad=$ Equity prices

$\lambda^{\mathrm{h}} \quad=$ Bankruptcy penalties imposed on investors

$\lambda^{\mathrm{b}} \quad=$ Bankruptcy penalties imposed on banks

ELA = Emergency Liquidity Assistance 
Financial instability manifests itself through the presence of endogenously determined default. Figure 2, shows how monetary, fiscal and regulatory policy affect financial instability.

\section{FIGURE 2}

\section{HOW POLICY AFFECTS FINANCIAL INSTABILITY}

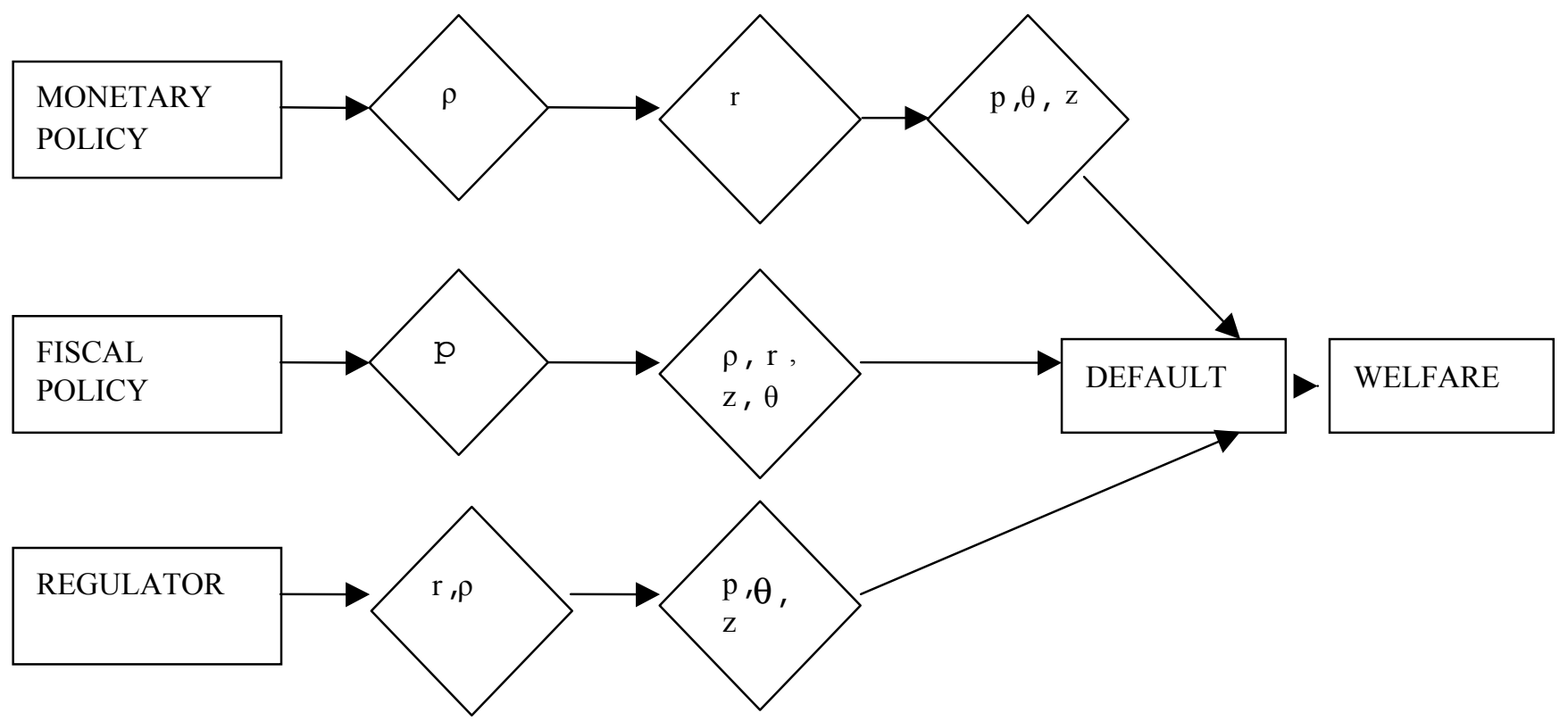

${ }^{1}$ Variables are denoted with the same symbols as in figure 1.

${ }^{2}$ Note that the direct channels only are indicated and I have omitted the channels and the effects that the equilibrating mechanisms of the various markets generate.

${ }^{3}$ As discussed below, default here does not necessarily imply welfare losses since the cost of default may be outweighed by the purchasing power of excess liquidity.

Monetary policy determines the interbank interest rate $(\rho)$ which in turn affects, via the actions of commercial banks, the term structure of interest rates in the credit markets $(r)$. In equilibrium, commodity and asset prices are established and default levels are optimising choices of commercial banks and the NBPS. Given specific bankruptcy penalties and regulatory minimum risk-weighted asset ratios, investors and banks rationally weight the marginal benefit versus the cost of defaulting in forming their portfolios. For example, if bankruptcy penalties were infinitely high then default would be prevented altogether but at the expense of welfare improving transactions and investments that might require a less risk-averse attitude. In other words, there exists a trade-off between the severity of the bankruptcy code and investment behaviour in the economy.

Similarly, fiscal policy operates through the commodity markets, which then affect the credit, equity and asset markets. In addition, the government may be engaged in capital injections by directly providing equity capital to individual commercial banks (as was the case, for example, in the Swedish and Japanese banking crises in the early 1990s). Finally, regulatory policy, either through the default penalty $(\lambda)$ or capital adequacy ratio $(\kappa)$, establishes respectively a lower and an upper bound on interest rates. In particular, $\kappa$ sets a ceiling for the maximum bank credit expansion given the central banks monetary policy. Similarly, the specification of $\lambda$ imposes a floor on prices below which the marginal cost of default exceeds the marginal benefit, and therefore determines a lower bound on interest rates. 


\subsection{The Time Structure of Markets}

In each time period the following market transactions occur:

At $t=0$, the commodity, asset, equity, credit (long and short) and interbank markets meet. At the end of the first period consumption and settlement (i.e., principal, interest rate and bankruptcy penalties payment) of the one-period loans take place.

At $t=1$, the commodity and short-term credit markets meet, and long-term loans and assets are delivered. At the end of the second period consumption and settlement of the interbank, long-term and second period short-term loans defaults take place. Capital requirements need to be met at the end of each period for each state.

Figure 4, makes the time line of the model explicit. It includes the various moments at which the different loans are due. The ordering of the markets is unimportant if the time horizon $T$ is large (and if goods are durable). The specific order shown (with credit markets first) is shown so as to maximise the amount of possible trading activity per period since the focus is on events stemming from the financial sector of the economy.

Note that fiscal policy and bankruptcy settlements occur in both periods and money financed fiscal transfers occur at every $s \in S^{*}$ before any activity has taken place. Lender of Last Resort support (LOLR) to individual banks is understood as money financed fiscal transfers to commercial banks. Also, liquidity injections in the interbank market can be thought of as aggregate LOLR support to the market in response to an exogenous adverse shock. An example is Federal Reserve intervention in the aftermath of the 1998 Asian crisis. This type of intervention is tantamount to Emergency Liquidity Assistance (ELA) to the market as a whole. ${ }^{15}$

\footnotetext{
${ }^{15}$ In order to minimise moral hazard, central banks do not usually preannounce or set specific criteria for LOLR preferring instead a policy of "constructive ambiguity".
} 
FIGURE 3

TIME STRUCTURE OF THE MODEL

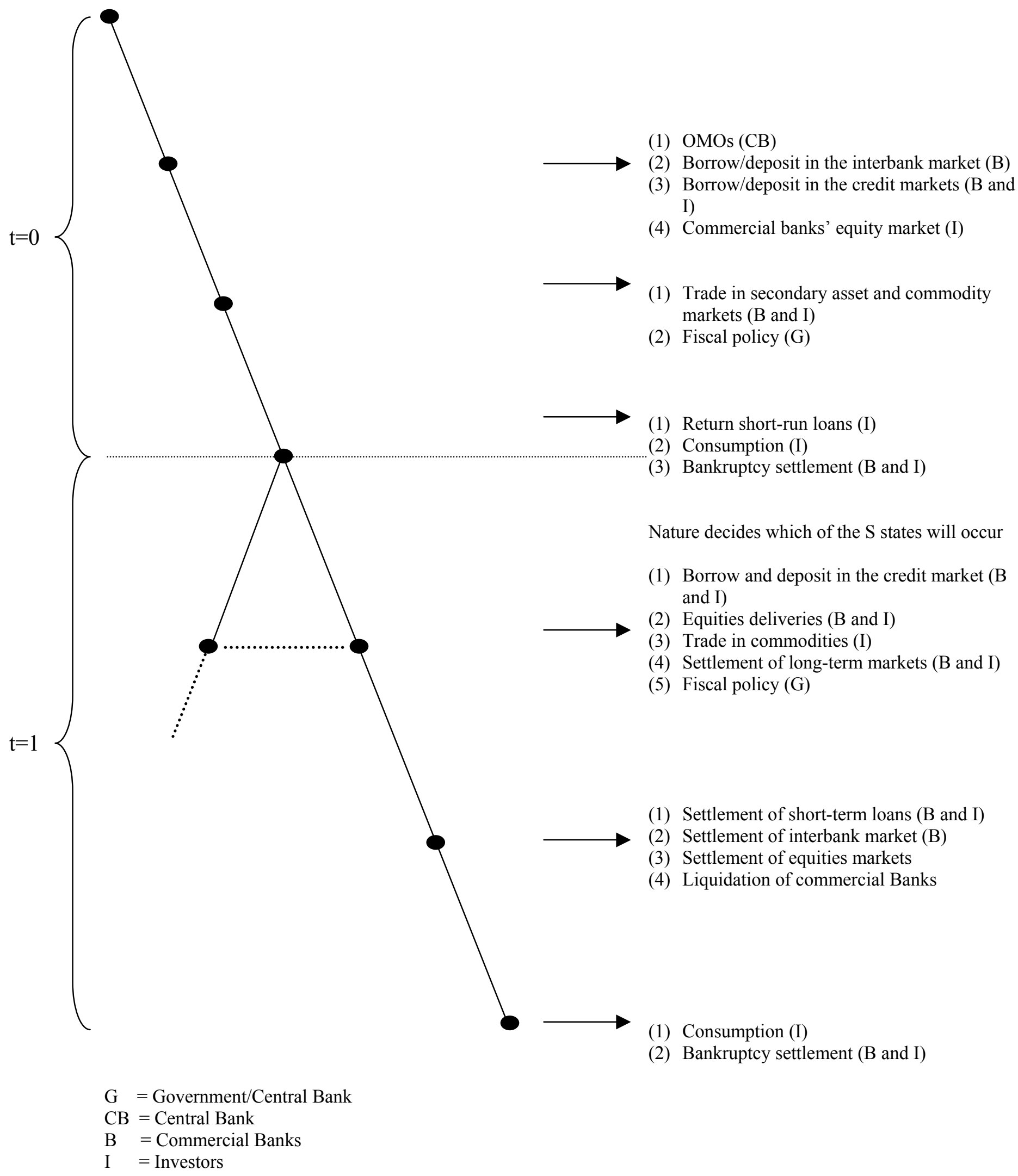

Without loss of generality, I present a two-period version of the model. The same sequence of transactions apply for any finite horizon (i.e., $T=(0,1 \ldots T)$ ). 


\subsection{Asset Markets}

The set of assets is $J=\{1, \ldots J\}$. Assets are promises sold by the seller in exchange for a price paid by the buyer today. They are traded at $t=0$ and the contractual obligations are delivered at $t=1$ at a particular state $s \in S$. An asset $j \in J$ is denoted by a vector $A^{j} \in R_{+}^{S(L+1)}$ indicating the collection of goods deliverable plus the money at any future state $s \in S$. Therefore, the asset market is summarised by an $((L+1) S) \times J$ matrix:

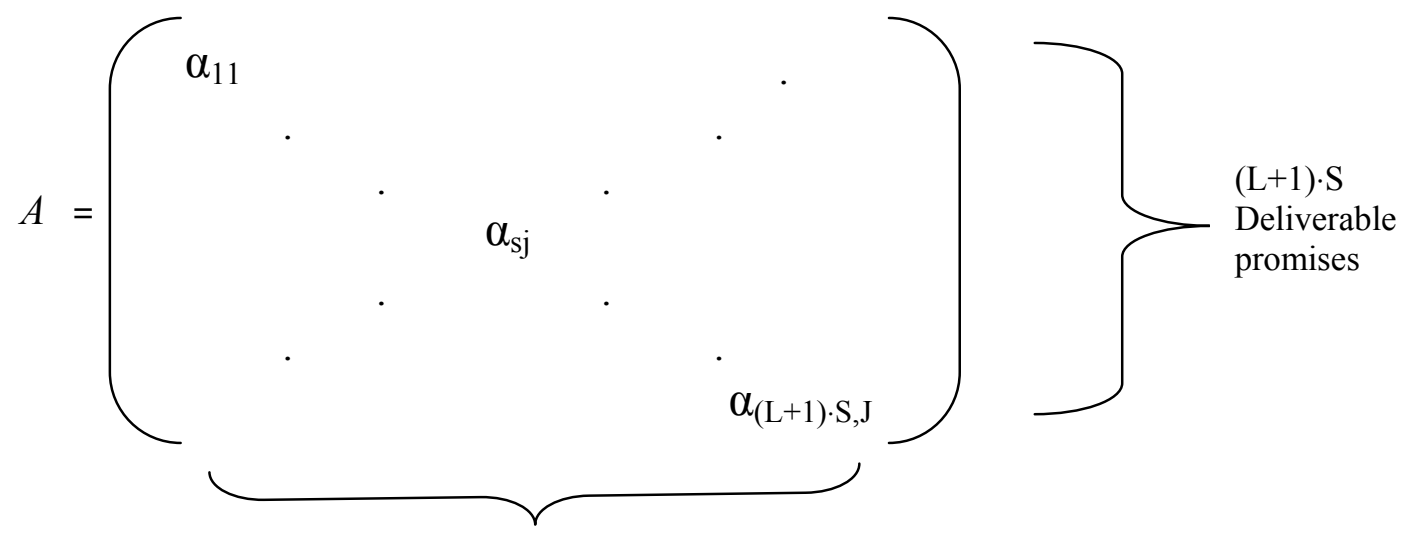

J Assets

All the deliveries are made in money. When the assets promise commodities the seller of the assets delivers the money equivalent of the value of the agreed commodities at their spot prices at the relevant state. The set of assets that are admissible is quite general ${ }^{16}$, however I restrict my attention to the "canonical" asset matrix without loss of generality.

The most characteristic asset in our model is the riskless asset, which promises money in all states, i.e., $A_{s m}^{j}=1, \forall s \in S$. Moreover, a financial asset is one that $A_{s l}^{j}=0, \forall l \in L, s \in S$. The column rank of A is critical since it describes the structure of the asset market. Whenever $\operatorname{rank}|J|=\operatorname{rank}|S|$ the capital markets are said to be complete whereas when $\operatorname{rank}|J|<\operatorname{rank}|S|$ the markets are said to be incomplete. The case when some assets are missing is the most interesting one because in addition to its realism it allows for the study of financial innovation, government intervention and a multitude of other interesting macroeconomic phenomena. ${ }^{17}$

Furthermore,

(A6) $A^{j} \neq 0, \forall j \in J$.

(i.e., no asset makes zero promises.)

\footnotetext{
${ }^{16}$ I could have easily incorporated quantity constraints, limited participation and collateral without affecting the existence of equilibria. (see, section 11)

${ }^{17}$ Market incompleteness is assumed rather derived. For more on this see [22].
} 
(A7) $A^{j} \geq 0, \forall j \in J$.

(i.e., asset payoffs are non-negative.)

Finally, agents do not hold positive endowments of assets and thus all asset transactions are short sales. ${ }^{18}$

In the spirit of perfect competition asset prices facing individuals are fixed. Let $b_{j}^{h} \equiv$ amount of money sent by agent $h$ in the market of asset $j$. Also, let $q_{j}^{h} \equiv$ promises sold of asset $j$ by agent $h \in H$. In equilibrium, at positive levels of trade $0<\theta_{j}<\propto$,

$$
\theta_{j}=\frac{\sum_{h \in H} b_{j}^{h}+\sum_{b \in B} b_{j}^{b}}{\sum_{h \in H} q_{j}^{h}+\sum_{b \in B} q_{j}^{b}},
$$

for $j \in J, h \in H, b \in B$. All the asset markets meet contemporaneously; hence cash obtained from the sale of asset $j$ cannot be used for the purchase of another asset $j^{\prime} \neq j$. Thus, the volume of trade in the asset market is affected by the overall liquidity of the economy. This way monetary policy interacts with asset markets and influences asset prices. ${ }^{19}$

\subsection{Money and Credit Markets}

Fiat money is the stipulated means of exchange. All commodities can be traded for money, and (as noted) all assets deliver exclusively in money. Money can be either inside or outside (Gurley and Shaw [34]). At the outset NBPS and banks hold net monetary assets -outside money- (i.e., as if they hold central bank liabilities). Inside money is credit created by the banking sector through the credit markets in period 0 via monetary policy and is accompanied by debt. Commercial banks receive central bank money as an asset but simultaneously incur a debt liability. In turn, commercial banks lend to the non-bank private sector. This represents an asset of the commercial bank and thus a liability of the non-bank private sector. The net assets of the private sector as a whole remain unchanged.

Cash-in-advance is required for any purchase. ${ }^{20}$ To buy a commodity or bond an agent must pay cash, which he can obtain from his private monetary endowments, or out of inventories from previous market transactions. Since fiat money is the stipulated means of exchange, transactions in each market have a convenient physical interpretation according to which money is traded for equal

\footnotetext{
${ }^{18}$ The model could have extended straightforwardly to incorporate positive endowments of assets but would not meaningful in the absence of a stock market and production.

${ }^{19}$ Since liquidity affects asset prices, the asset price inflation channel of monetary policy is present in the model.

${ }^{20}$ One should not interpret the cash-in-advance as a currency constraint but rather as a liquidity constraint. This is so because, I could have assigned liquidity parameters for each commodity and use the ensuing liquidity constraints. The main feature of the cash in advance constraint is the asymmetry of liquidity capabilities of the postulated means of exchange as compared with the rest of commodities. For example, Grandmont and Younes [28] assign a liquidity parameter in the cash-in-advance constraint.
} 
value of commodities or bonds. If interest rates are positive the necessity to have cash in order to purchase commodities invalidates the 'classical' dichotomy between the real and financial sectors of the economy.

Market is regarded as a symmetric exchange between two instruments. In standard Arrow-Debreu terminology, a market bears only one name. Since in this model, money is always one of the instruments, I too can give each market a single name, but one could easily imagine other markets (e.g. for credit card purchases) where neither side was cash; for more discussion see Dubey and Geanakoplos [22]. Just as agents cannot "sell" money they do not have in a market, so in the model agents cannot sell commodities they do not have. The only exception is credit markets, where we allow agents to write their own promises (bonds). ${ }^{21}$

Money enters the economy in three ways. First, it may be present in the private endowments of agents and commercial banks. Agent $h \in H$ has an endowment $m_{s}^{h}$ of money, for each $s \in S^{*}$ and commercial banks have initial capital endowment $e_{s}^{b}$, for each $s \in S^{*}$. Second, when government and/or the Central Bank) purchases commodities and/or bonds with currency, it injects money in the economy. Third, when the government (perhaps through the Central Bank) repays previously issued government bonds, it also injects money in the economy. The channel by which money enters the economy influences the effect the money has on the economy, as we shall see in greater detail later on. Money exits the system in two ways: bonds from investors/households and payment on bonds (promises) sold to the government.

Two kinds of bond (equivalently credit or loan) markets can be distinguished. Short-term (intraperiod or overnight) bonds promise 1 unit of fiat money at the end of the same period in which they are taken. Long-term (interperiod) bonds promise 1 unit of money at the beginning of the next period, but after the next short loan begins. ${ }^{22}$ Note that long-term loans can be thought of as oneperiod zero coupon bonds.

By rolling over a long loan to the next short loan to the next long loan, agents can borrow against any future time period. Let $r_{s}, \bar{r}$ be the interest rates on the short and long-term loans respectively. An agent who borrows $\varepsilon$ in the intraperiod (interperiod) loan market owes $\left(1+r_{s}\right) \varepsilon((1+\bar{r}) \varepsilon)$ at the end of state $s \in S^{*}$ (at the beginning of period 1 ). Agents regard the interest rates as fixed.

The bank has exogenously specified positive quantities of money $\left(M^{G}\right)$, which it auctions off in the interbank bond market. The bank also sells bonds $\left(\mu^{G}\right)$ in the same market.

Agents are permitted to deposit money at the commercial banks where they earn the same interest rate as the banks charge.

Note that one should not expect $r_{o}=\bar{r}$. Typically, the equilibrium term structure can be quite complex and depends on the multiple factors that influence the demand for money. ${ }^{23}$

\footnotetext{
${ }^{21}$ An alternative interpretation of the cash in advance constraint is that financial markets clear immediately whereas commodity markets adjust sluggishly.

22 Since each seller does not know what other promises each buyer has made and in addition the buyer has the option to default we are faced with a moral hazard problem. However, the moral hazard problem arises from opportunistic behaviour in a competitive environment.

${ }^{23}$ Both the expectations and the liquidity preference hypothesis of the term structure of interest rates jointly determine the term structure of interest rates.
} 
Agents are permitted to buy and sell bonds, i.e., to borrow and deposit money in the consumer credit markets. Let $\mu_{s}^{h}\left(\operatorname{or} \bar{\mu}^{h}\right)$ be the amount of zero-coupon bonds issued by $h \in H$, or equivalently, the amount of money agent $h$ chooses to owe on the short loan (or long loan). Let $d_{s}^{h}\left(\right.$ or $\left.\bar{d}^{h}\right)$ be the amount of money that agent $h \in H$ spends on purchases of short-term (long-term) bonds. If all agents pay exactly what they owe, then we must have that,

$$
\left(1+r_{s}\right)=\frac{\sum_{h \in H} \mu_{s}^{h}}{\sum_{h \in H} d_{s}^{h}+\sum_{b \in B} m_{s}^{b}} \quad, \quad \forall s \in\{0,1, \ldots, S\}
$$

and

$$
(1+\bar{r})=\frac{\sum_{h \in H} \bar{\mu}^{h}}{\sum_{h \in H} \bar{d}^{h}+\sum_{b \in B} \bar{m}^{b}},
$$

where, $m_{s}^{b}\left(\bar{m}^{b}\right)$ is the amount of credit that commercial banks extend which is also subject to their capital-adequacy ratio as specified by the regulator.

Note that bonds and assets are the only instruments that agents and banks are allowed to sell without essentially owning them. Indeed, any agent $h$ can write out his own promise, which then becomes a bond. However, $h$ is limited in how many he can sell by the bankruptcy code, which contributes to the determination of equilibrium. ${ }^{24}$

Bonds, money and assets can be inventoried; they are the only stores of value in our model. Neither provides utility directly to the agents.

\subsection{Default}

Under the presence of uncertainty and agent optimisation default can be either strategic or due to illfortune. Lenders cannot distinguish whether default occurs because the debtors are unable to honour their contractual obligations or they chose to do so even though they have the necessary resources. The default penalties will be proportional to the level of default and its purpose is to induce debtors to honour their obligations when they are able to do so and to refrain from making promises that they know they will not honour in the future.

Let $\Omega=\{N\} \cup\{J\}=\left\{0^{*}, \overline{0}, 0,1, \ldots, S\right\} \cup\{1, \ldots, J\} . \Omega$ is the set of all credit markets (including the interbank $)$ and secondary asset markets $\left(0^{*} \equiv\right.$ interbank, $\overline{0} \equiv$ long - term credit market, $0,1, \ldots, S \equiv$ short - term credit market). Let us define $D_{s \omega}^{h}=\left(1-v_{s \omega}^{h}\right) \mu_{s}^{h}\left(D_{s \omega}^{b}=\left(1-v_{s \omega}^{b}\right) \mu^{b}\right)$ where

\footnotetext{
${ }^{24}$ See also footnote 1.
} 
$v_{s \omega}^{h}\left(v_{s \omega}^{b}\right)$ is the rate of repayment by households (banks). $D_{s \omega}^{h}$ is the nominal value of debt due to default either in the credit markets (analogously in the asset market or deposits and interest rate obligations). In practice, default penalties and the bankruptcy code depend normally on the nominal values of debt and are adjusted at discrete intervals as the general level of prices increases. In the model, nominal values are deflated so as to penalise households and banks on "real" default. ${ }^{25}$

The parameters $\lambda_{s \omega}^{h}\left(\lambda_{s \omega}^{b}\right)$ to represent the marginal disutility of defaulting for each "real" dollar on assets or loans in state s. Therefore, the payoffs to investors/households and commercial banks will be respectively $\forall s \in S^{*}$,

$$
\Pi_{s}^{h}\left(x_{s}^{h},\left(D_{s \omega}^{h}\right)_{\omega \in \Omega}, p_{s}\right)=u_{s}^{h}\left(x_{s}\right)-\frac{\sum_{\omega \in \Omega} \lambda_{s \omega}^{h}\left[D_{s \omega}^{h}\right]^{+}}{p_{s} g_{s}}
$$

and

$$
\Pi_{s}^{b}\left(\pi_{s}^{b},\left(D_{s \omega}^{b}\right)_{\omega \in \Omega}, p_{s}\right)=u_{s}^{b}\left(\pi_{s}^{b}\right)-\frac{\sum_{\omega \in \Omega} \lambda_{s \omega}^{b}\left[D_{s \omega}^{b}\right]^{+}}{p_{s} g_{s}},
$$

where $g_{s}$ is the base basket of goods which serves as a price deflator with respect to which the bankruptcy penalty is measured and

$$
[c]^{+} \equiv \max [0, c]
$$

The specification of default captures the idea (first introduced by Shubik and Wilson [56]) that the utility decreases monotonically in the level of default. ${ }^{26}$ In equilibrium, agents equalise the marginal utility of defaulting with the marginal disutility of the bankruptcy penalty. Thus, expected rates of delivery of interbank, long-term, short-term in $s=0$, short-term loans for all $s \in S$, for assets, and analogously for deposits $R=\left(\widetilde{R}_{s}, \bar{R}_{s}, R_{s}, R_{s j}, \widetilde{\mathrm{R}}_{\mathrm{ds}}, \overline{\mathrm{R}}_{\mathrm{ds}}, \mathrm{R}_{\mathrm{ds}}\right) \forall s \in S^{*}$ and $j \in J$, are equal to actual rates of delivery in equilibrium. ${ }^{27}$ This idea is precisely the crucial ingredient of the model. It allows us to establish default as an equilibrium outcome without necessarily destroying the orderly functioning of the financial system.

\footnotetext{
${ }^{25}$ Complicated structures of default penalties can be incorporated into the model as long as concavity of the payoff function is maintained. For further details on this topic see [17], [19]. Without loss of generality, a simple specification is used that assumes penalties are adjusted instantaneously following changes in the price level.

${ }^{26}$ Alternatively, I could have modelled default penalties by subtracting resources according to the $\lambda$ 's from the budget constraints of the agents. However, this technique is more complicated since the marginal disutility of default is not constant but directly affects the marginal rates of substitution of commodities as can be seen from the first order conditions. Detailed exposition of this more general default modelling methodology can be found in [60] where I treat this default specification as a special case of generalised default penalties.

${ }^{27}$ For a definition of rates of delivery and a necessary assumption that these expectations should satisfy, see section 4 .
} 


\subsection{Capital Requirements}

The regulator sets the banks' minimum capital requirements. Given that the assets of the commercial banks consist of loans (including interest rate payments ${ }^{28}$ ) and their asset investments, the capital requirement constraint becomes,

$$
k_{b s} \leq \frac{e_{s}^{b}+\sum_{h \in H} u_{b}^{h}+c_{s}^{b}}{w_{s s}^{b}(\eta, \sigma) R_{s} m_{s}^{b}\left(1+r_{s}\right)+w_{s 0}^{b}(\eta, \sigma) \bar{R}_{s} \bar{m}^{b}(1+\bar{r})+\sum_{j \in J} w_{s j}^{b}(\eta, \sigma) R_{s j}\left(p_{s} A_{s}^{j}\right)\left(\frac{b_{j}^{b}}{\theta_{j}}\right)+w_{s 0^{*}}^{b} \widetilde{R}_{d s}(1+\rho) d^{b}}
$$

$\forall s \in S, b \in B$

and

$$
k_{b 0} \leq \frac{e_{0}^{b}+\sum_{h \in H} u_{b}^{h}+c_{0}^{b}}{w_{00}^{b}(\eta, \sigma) R_{0} m_{0}^{b}\left(1+r_{0}\right)+w_{0 \overline{0}}^{b}(\eta, \sigma) \bar{m}^{b}(1+\bar{r})+\sum_{j \in J} w_{0 j}^{b}(\eta, \sigma)\left(p_{s} A_{s}^{j}\right)\left(\frac{b_{j}^{b}}{\theta_{j}}\right)+w_{00^{*}}^{b}(\eta, \sigma)(1+\rho) d^{b}},
$$

for $s=0$,

where, $w_{0 s}^{b} \equiv$ risk weights for short term loans, $w_{s \overline{0}}^{b} \equiv$ risk weights for long term loans, $w_{s 0^{*}}^{b} \equiv$ risk weights for interbank loans, $w_{s j}, \forall j \in J \equiv$ risk weights for assets that the regulator establishes for the valuation of the bank's assets, $\eta \equiv$ set of macrovariables, and $\sigma \equiv$ choice variables of households and commercial banks. ${ }^{29}$ In addition, $\sum_{h \in H} u_{b}^{h} \equiv$ initial equity of commercial banks and $c_{s}^{b} \equiv$ capital adjustment. Thus, commercial banks decide on any capital adjustment jointly with the structuring of their portfolio to satisfy their capital requirements constraint. Banks may not necessarilly hold the same capital since the precautionary capital over and above the regulatory minimum can vary across banks. ${ }^{30}$ Note that credit requirements are calculated with respect to the realised asset deliveries in equilibrium and not the expected ones.

The impact of regulatory policy is similar to the ones of monetary policy since it affects credit extension, although it operate through different channels. Also, the time varying risk weights are consistent with the New Basel Accord.

Finally, it should be noted that increased default reduces utility but it may also have a counterbalancing effect. If risk weights were countercyclical, higher defaults, as would occur in a recession, would lead banks to reduce their risk weights in the expectation that future economic conditions would improve. In turn, if capital constraint were binding, lower risk weights would allow

\footnotetext{
28 Interest rate payments paid on loans are considered assets since they represent investors' obligations payable to the bank. Also, I assume, as it is evident from the budget constraint of the commercial banks (see section 3.2), that they are reinvested totally.

${ }^{29}$ The risk weights may or may not be invariant. For example, they may be time varying and depend on other macrovariables or choices of investors and/or banks. Catarineu-Rabell and Tsomocos [49] examine the case where they depend on investors' default either procyclically or countercyclically.

${ }^{30}$ Since commercial banks almost always observe their capital requirement constraint, I do not need to establish default penalties for their violation. However, this could have been very easily incorporated into the model.
} 
for an increasing credit extension that reduces interest rates and thus facilitates transactions. ${ }^{31}$ Thus, utility may very well increase if the latter effect dominates the former. In such a situation capital requirements may be thought of as a built-in-stabiliser of the economy.

\subsection{The Commodity Markets}

Commodity prices $p_{s l}$ are taken to be fixed by the agents. Let $b_{s l}^{h} \equiv$ amount of fiat money sent by agent $h$ to trade in the market of commodity $s l \in L$. In addition, let $q_{s l}^{h} \equiv$ amount of good $l$ offered for sale at state $s$ by agent $h$. In Agents cannot sell commodities they do not own, so $q_{s l}^{h} \leq e_{s l}^{h}$. Let $b_{s l}^{G} \equiv$ amount of fiat money that the government puts up to buy commodity $s l \in L$. Government expenditures are taken as exogenous and are meant to capture fiscal policy. In equilibrium, at positive levels of trade, $0<p_{s l}<\infty$,

$$
p_{s l}=\frac{\sum_{h \in H} b_{s l}^{h}+b_{s l}^{G}}{\sum_{h \in H} q_{s l}^{h}} .
$$

All markets meet simultaneously; hence cash obtained from the sale of commodity $l$ at state $s$ cannot be used for the purchase of another commodity $l$ at the same state. This institutional arrangement is the fundamental feature of the model that captures the importance of liquidity constraints and the transactions demand for cash. Liquidity constraints should not be viewed as market imperfections but rather as the intrinsic characteristic that distinguishes commodities from liquid wealth. ${ }^{32}$

\subsection{Stocks, Flows and Liquidity Constraints}

In the abstract Arrow-Debreu model it is difficult to distinguish stocks and flows, especially when public production is involved. Even when they can be distinguished formally, there is no importance in the distinction; one might as well assume that every good is bought and sold each period. In the Lucas (exchange economy) model, agents are required to put everything up for sale in each period, so there can be no distinction between stocks and flows.

However, in stark contrast, in my model the sales $q_{s l}^{h}$ of commodities by agents are endogenous, agents are not required to put anything for sale. Indeed, since sales equal purchases in equilibrium, the total quantity of sales is a good measure of aggregate economic activity (in Lucas it is essentially exogenous).

\footnotetext{
31 See E. Catarineu-Rabell and D.P.Tsomocos [10].

${ }^{32}$ This price formation mechanism first introduced by L. Shapley and M. Shubik [51], is an equilibrium condition. Its accounting clarity allows of cash flows in the economy to be traced precisely.
} 
$Y_{s}=\sum_{l \in L} \sum_{h \in H} p_{s l} q_{s l}^{h}$ and $\bar{y}_{s}=\sum_{l \in L} \sum_{h \in H} q_{s l}^{h}$ are the nominal and real incomes of agents at the state $s \in S^{*}$ respectively. They are endogenous variables. ${ }^{33}$

As was emphasised in the introduction, the process-oriented nature of all transactions assigns to them a physical interpretation and preserves accounting clarity. The receipts from sales of goods and assets cannot be used contemporaneously for purchases. This mismatch between cash outflows and inflows in an agent's budget is intermediated by the credit markets and the supply of credit by commercial banks. The same argument applies for commercial banks and their corresponding assetliquidity mismatch that the interbank credit market intermediates. Therefore, the endogenous determination of interest rates on the various credit markets may be such that investors and/or commercial banks are liquidity constrained. The credit channel of the model manifests itself in the determination and the extent to which liquidity constraints are binding and generate real effects in consumption. In particular, the repercussions of financial crises require the ability to distinguish between stocks and flows. Financially unstable regimes affect the flows of economic transactions and only after a lag is the impact on the stock variables of the economy observed. For example, a liquidity crisis first reduces the volume of trade and subsequently, perhaps, reduces the profitability of the banking sector.

\subsection{Commercial Banks}

Commercial banks enter the model because of their importance both for the transmission of monetary policy and for financial stability. The risk profiles of commercial banks have an effect on both liquidity and the credit expansion of the economy. Consequently, the money supply multiplier of the economy depends on the portfolio of the banking sector. Thus, equilibrium outcomes of the economy and the effectiveness of monetary policy depend on the banking sector.

Let $b \in B=\{1, \ldots, B\}$ be the set of commercial banks. We assume:

(A8) perfectly competitive banking sector (i.e., commercial banks take interbank interest rates and asset prices as fixed).

(A9) perfect financial intermediation (i.e., no market imperfections with respect to information and participation in the capital and credit markets).

An important consequence of (A8) and (A9) is that there is no margin between borrowing and lending rates.

Recall that each bank has an initial capital endowment and its risk profile is described by a concave, monotonic and continuous utility function:

$u^{b}=R_{+}^{s^{*}} \rightarrow R$

where, $u^{b}\left(\pi_{0}^{b}, \pi_{1}^{b}, \ldots, \pi_{s}^{b}\right)$ represents the utility to a bank $b$ when its final monetary holdings in $\mathrm{s} \in \mathrm{S}^{*}$ is $\pi_{s}^{b}$.

\footnotetext{
${ }^{33}$ The real income is an arbitrary number since it depends on the units in which we measure goods. Some policy changes, however, will increase $\bar{Y}_{s}$ no matter how we measure the units.
} 
Commercial banks participate in the interbank market by borrowing and lending. They then extend credit to the consumer credit markets and allocate the appropriate capital to satisfy their capital requirement constraint. Moreover, commercial banks diversify their portfolios by also investing in the asset markets. Thus, the model can encompass the interaction between monetary policy and the asset markets. The modelling of the banking behaviour is akin to the portfolio balance approach of the banking firm introduced by Tobin [57], [58].

As can be seen from the market structure of the model, at the beginning of period zero an equity market operates in which banks issue equity to the investors. Shares of ownership of the bank are determined on a prorated manner according to the formula ${ }^{34}$,

$$
s_{b}^{h}=\frac{u_{b}^{h}}{\sum_{h \in H} u_{b}^{h}}
$$

where, $u_{b}^{h} \equiv$ amount of money offered by $h$ for ownership shares of banks $b \in B .^{35}$

Finally at $t=1$ the profits of commercial banks are liquidated and distributed back to the individual owners according to their ownership shares. This way I close the model.

An important phenomenon that now appears is that not all the investors will defray their loans and that not all banks might honour their contractual obligations. The different risk-attitudes and the bankruptcy penalties imposed on defaulting banks make this compatible with equilibrium.

A simplified version of the bank's balance sheet is:

$($ Deposits $)+($ Equity $)=(\text { Required Reserves })^{36}+($ Loans $)+($ Interbank Deposits $)+($ Asset Investments $)$.

Deposits and loans arise from other commercial banks and from investors/households. Equity consists of initial capital endowment, initial equity and capital adjustments. Asset investment may appear in the asset or the liability side of the balance sheet depending on whether the bank is long or short on a particular asset.

\subsection{Interbank Credit Market}

The Central Bank conducts its monetary policy through OMO's in the interbank market. Also, interbank lending and borrowing occurs in this market. The existence of this market establishes interbank linkages and in the case of default causes a domino effect. Since perfect financial intermediation is assumed default is prorated among all the lenders. Thus, contagion and interbank linkages are equilibrium phenomena that manifest themselves via the perfect intermediation and do not necessarily require oligopolistic (or monopolistic competition) market structure or other market imperfections.

\footnotetext{
${ }^{34}$ When the model extends more than two periods then dilution of the existing ownership structure can be introduced by allowing retrading of the ownership shares of the banks. However, this extension would be more appropriate after I introduce production into the model and we analyse the capital structure of banks and firms.

${ }^{35}$ It would be redundant to allow commercial banks to bid for each other's shares since the ultimate shareholders of the banks are the investors themselves and the horizon is finite.

36 Required reserves need to satisfy the required reserve ratio if the monetary authority has established one. For simplicity, I do not include it in the model.
} 
The interbank interest rate is established in equilibrium at positive levels of trade,

$$
(1+\rho)=\frac{\sum_{b \in B} \mu^{b}+\mu^{G}}{\sum_{b \in B} d^{b}+M^{G}}
$$

where, $\mu^{b} \equiv$ amount of zero-coupon bonds issued by bank $b$, or equivalently the amount of money bank $b$ chooses to owe in the interbank credit market, $d^{b} \equiv$ amount of money that bank $b$ deposits, or equivalently the amount of money that bank $b$ spends on purchases of bonds. Similarly, $\mu^{G} \equiv$ amount of zero-coupon bonds issued by the central bank and $M^{G} \equiv$ central bank money supply or equivalently the amount of money the central bank spends on purchases of bonds. ${ }^{37}$

In practise monetary authorities use the repo market to set interest rates and then commercial banks participate in the interbank market. I collapse both markets in one because the monetary transmission mechanism remains the same apart from multiplier effects in the context of this model. The separation of these markets is necessary when the focus is on the transmission mechanism of monetary policy.

Both in investors/households credit markets and the interbank market default is allowed; so bonds and currency are not perfect substitutes as it would be the case if there was no default. Assets and bonds are the only instruments agents are allowed to sell without owning. Essentially any agent can write his own promise, which then becomes a bond. However, he is limited in how many he can issue by the bankruptcy penalties that prevent him from going arbitrarily short. Assets, bonds and money can be inventoried from period 0 to period 1 and thus they are the only stores of value in the model. None of these instruments gives direct utility to the agents. Utility is derived only through the results of transactions they facilitate.

\section{The Budget Set}

It is assumed that commodities are perishable lasting only one period, and that each market meets once in each period. Aside from putting an upper bound on the velocity of money, the drawback of this simplification is that order in which the markets meet needs to be carefully chosen. ${ }^{38}$ The reason of this is to maintain the cash in advance requirement (i.e., to ensure that agents have the money before they spend). Accordingly, at the beginning of each period, intraperiod bank loans are available so that agents can borrow the cash to make purchases. The timing of the interperiod loan does not matter, as long as agents can roll over loans by alternating short and long loans. The sequence of moves is indicated in figure 4 . Note that there are three sub-periods in each period. The endowments, the prices, and the timing of markets impose various constraints on the cash balances of the agents.

\footnotetext{
${ }^{37}$ Instead of conducting OMOs, the Central Bank could determine the interest rate letting borrowing and lending with commercial banks equilibrate the market. In fact, this is the current practice of implementing monetary policy. The crucial point is that the Central Bank has one degree of freedom and therefore can use only one of the two policy instruments.

${ }^{38}$ These problems are avoided with durable goods. In that case the periods could be regarded as arbitrarily close together and the order of market transactions inside a period would become irrelevant. If market $\alpha$ preceded market $\beta$ inside each period, an agent could always trade on market $\beta$ in period $t$ and then wait a 'nanosecond' to trade in market $\alpha$ in period $t+1$ if that is the order he preferred.
} 


\subsection{Investors}

The macro variables which are determined in equilibrium, and which every agent regards as fixed, are denoted by $\eta=\left(p, \rho, r_{s}, \bar{r}, \theta, R\right)$. The choices of the NBPS $h \in H$, are denoted by $\sigma^{h} \in \Sigma^{h}(\eta)$

where,

$$
\sigma^{h}=\left(\chi^{h}, \bar{\mu}^{h}, \mu^{h}, d^{h}, \bar{d}^{h}, b^{h}, q^{h}, u^{h}, v^{h}\right) \in R_{+}^{L S^{*}} \times R_{+} \times R_{+}^{S^{*}} \times R_{+}^{S^{*}} \times R_{+} \times R_{+}^{L S^{*}+} \times R_{+}^{L S^{*} J} \times R_{+}^{B} \times R_{+}^{S^{*} J+1}
$$

is the vector of all of investors' decisions. Denote the macro variables which are determined in equilibrium, and which every agent regards as fixed, by $\eta=\left(p, \rho, r_{s}, \bar{r}, \theta, R\right)$. Denote the choices of an investor $h \in H, \sigma^{h} \in \Sigma^{h}(\eta)$

where,

$$
\sigma^{h}=\left(\chi^{h}, \bar{\mu}^{h}, \mu^{h}, d^{h}, \bar{d}^{h}, b^{h}, q^{h}, u^{h}, v^{h}\right) \in R_{+}^{L S^{*}} \times R_{+} \times R_{+}^{S^{*}} \times R_{+}^{S^{*}} \times R_{+} \times R_{+}^{L S^{*+J}} \times R_{+}^{L S^{*} J} \times R_{+}^{B} \times R_{+}^{S^{*} J+1}
$$

is the vector of all of his market decisions.

The variables represent the following quantities:

$\chi^{\mathrm{h}} \equiv$ consumption,

$\bar{\mu}^{h} \equiv$ long-term loan,

$\mu_{s}^{h} \equiv$ short-term loans at each $s \in S^{*}$,

$\bar{d}^{h} \equiv$ long-term deposits,

$d_{s}^{h} \equiv$ short-term deposits,

$b_{s l}^{h},\left(b_{j}^{h}\right) \equiv$ amounts of money offered in the goods (asset) markets,

$q_{s l}^{h},\left(q_{j}^{h}\right) \equiv$ sales of goods and assets,

$u^{h} \equiv$ bid for ownership shares of the commercial banks, and

$v_{n(j)}^{h},\left(\bar{v}_{s}^{h}\right) \equiv$ percentage deliveries of promised short-term loans, assets and long-term loans.

$B^{h}(\eta)=\left\{\sigma^{h} \in \Sigma^{h}(\eta):(1)-(10)\right.$ below $\}$ is the budget set, where $\Delta(\mathrm{i})$ represents the difference between RHS and LHS of inequality (i). 
For $t=0$,

$d_{0}^{h}+\bar{d}^{h} \leq m_{0}^{h}$

$\sum_{j \in J} b_{j}^{h}+\sum_{b \in B} u_{b}^{h}+\sum_{l \in L} b_{0 l}^{h} \leq \Delta\left(1^{h}\right)+\frac{\mu_{0}^{h}}{\left(1+r_{0}\right)}+\frac{\bar{\mu}^{h}}{(1+\bar{r})}$

$q_{0 l}^{h} \leq e_{0 l}^{h} \quad, \quad \forall l \in L$

$v_{0}^{h} \mu_{0}^{h} \leq \Delta\left(2^{h}\right)+\sum_{l \in L} p_{0 l} q_{0 l}^{h}+R_{0} d_{0}^{h}\left(1+r_{0}\right)+\sum_{j \in J} \theta_{j} q_{j}^{h}$

$x_{0 l}^{h} \leq e_{0 l}^{h}-q_{0 l}^{h}+\frac{b_{0 l}^{h}}{p_{0 l}}, \quad \forall l \in L$

$\forall s \in S$,

$d_{s}^{h} \leq \Delta\left(4^{h}\right)+m_{s}^{h}$

$\sum_{l \in L} b_{s l}^{h}+\sum_{j \in J}\left(v_{s j}^{h} p_{s} A_{s}^{j}\right) q_{j}^{h}+\bar{v}_{s}^{h} \bar{\mu}^{h} \leq \Delta\left(6^{h}\right)+\frac{\mu_{s}^{h}}{\left(1+r_{s}\right)}+\overline{R_{d s}} \bar{d}^{h}(1+\bar{r})$

$q_{s l}^{h} \leq e_{s l}^{h} \quad, \quad \forall l \in L$

$v_{s}^{h} \mu_{s}^{h} \leq \Delta\left(7^{h}\right)+\sum_{j \in J}\left(R_{s j} p_{s} A_{s}^{j}\right)\left(\frac{b_{j}^{h}}{\theta_{j}}\right)+R_{d s} d_{s}^{h}\left(1+r_{s}\right)+\sum_{b \in B}\left(\frac{u^{h}}{\sum_{h \in H} u^{h}}\right) \pi_{s}^{b}+\sum_{l \in L} p_{s l} q_{s l}^{h}$

$x_{s l}^{h} \leq e_{s l}^{h}-q_{s l}^{h}+\frac{b_{s l}^{h}}{p_{s l}} \quad, \quad \forall l \in L$.

\subsection{Commercial Banks}

Denote the choices of a commercial bank $b \in B, \sigma^{b} \in \Sigma^{b}(\eta)$, where $\sigma^{b}=\left(\mu^{b}, d^{b}, \bar{m}^{b}, m_{s}^{b}, b_{j}^{b}, q_{j}^{b}, c_{s}^{b}, v_{s}^{b}, \pi_{s}^{b}\right) \in R_{+} \times R_{+} \times R_{+} \times R_{+}^{S^{*}} \times R_{+}^{J} \times R_{+}^{J} \times R_{+}^{S^{*}} \times R_{+}^{S^{*}+J+2} \times R_{+}^{S^{*}}$ is the vector of all its market decisions.

The variables represent the following quantities:

$\mu^{b} \equiv$ interbank market loans,

$d^{b} \equiv$ interbank market lending (deposits), 
$m_{s}^{b} \equiv$ credit extension at the various short-term credit markets,

$m^{b} \equiv$ credit extension at the long term credit market,

$b_{j}^{b} \equiv$ amount of money offered for the purchase of assets,

$q_{j}^{b} \equiv$ sales of assets,

$c_{s}^{b} \equiv$ capital adjustment,

$v_{s(j)}^{b},\left(\bar{v}_{s}^{b}, \nu_{s}, \widetilde{v}_{s}^{b}\right) \equiv$ percentage deliveries of promised assets, interest rate payments on deposits and interbank loans

$\pi_{s}^{b} \equiv$ final monetary holdings (profits) in every state.

$B^{b}(\eta)=\left\{\sigma^{b} \in \Sigma^{b}(\eta):(1)-(7)\right.$ below $\}$, is the budget set, where $\Delta(\mathrm{i})$ represents the difference between RHS and LHS of inequality (i).

For $t=0$,

$d^{b} \leq e_{0}^{b}$

$m_{0}^{b}+\stackrel{-b}{m}^{b} \sum_{j \in J} b_{j}^{b} \leq\left(\Delta\left(1^{b}\right)+\frac{\mu^{b}}{(1+\rho)}+\sum_{h \in H} u_{b}^{h}\right)$

$\left(v_{0}\left(1+r_{0}\right) \sum_{h \in H} d_{0}^{h}\right) z_{0}+c_{0}^{b} \leq \Delta\left(2^{b}\right)+\left(R_{0} \sum_{h \in H} \mu_{0}^{h}\right) z_{0}+\sum_{j \in J} \theta_{j} q_{j}^{b}$

$k_{b 0} \leq \frac{e_{0}^{b}+\sum_{h \in H} u_{b}^{h}+c_{0}^{b}}{w_{00}^{b}(\eta, \sigma) R_{0} m_{0}^{b}\left(1+r_{0}\right)+w_{00}^{b}(\eta, \sigma) \bar{m}^{b}(1+\bar{r})+\sum_{j \in J} w_{0 j}^{b}(\eta, \sigma)\left(p_{s} A_{s}^{j}\right)\left(\frac{b_{j}^{b}}{\theta_{j}}\right)+w_{00^{*}}^{b}(\eta, \sigma)(1+\rho) d^{b}}$

$\forall s \in S$,

$m_{s}^{b}+\left(\sum_{h \in H} \bar{\nu}_{s}^{b}(1+\bar{r}) \bar{d}^{h}\right) \bar{z} \leq \Delta\left(3^{b}\right)+\left(\sum_{h \in H} \bar{R}_{s} \bar{\mu}^{h}\right) \bar{z}+e_{s}^{b}=\pi_{0}^{b}$

$c_{s}^{b}+\sum_{h \in H} v_{s}^{b} d_{s}^{h}\left(1+r_{s}\right) z_{s}+\left(v_{s}(1+\rho) \sum_{b \in B} d^{b}\right) z+\widetilde{v}_{s}^{b} \mu^{b}+\sum_{j \in J} v_{s j}^{b} p_{s} A_{s}^{j} q_{j}^{b} \leq$

$\Delta\left(5^{b}\right)+\sum_{j \in J}\left(R_{j} p_{s} A_{s}^{j}\right)\left(\frac{b_{j}^{b}}{\theta_{j}}\right)+\widetilde{R}_{\mathrm{ds}} d^{b}(1+\rho) z+\left(\sum_{h \in H} R_{s} \mu_{s}^{h}\right) z_{s}$ 


$$
k_{b s} \leq \frac{e_{s}^{b}+\sum_{h \in H} u_{b}^{h}+c_{s}^{b}}{w_{s s}^{b}(\eta, \sigma) R_{s} m_{s}^{b}\left(1+r_{s}\right)+w_{s 0}^{b}(\eta, \sigma) \bar{R}_{s} \bar{m}^{b}(1+\bar{r})+\sum_{j \in J} w_{s j}^{b}(\eta, \sigma) R_{s j}\left(p_{s} A_{s}^{j}\right)\left(\frac{b_{j}^{b}}{\theta_{j}}\right)+w_{s 0^{*}}^{b} \widetilde{R}_{d s}(1+\rho) d^{b}}
$$

where, $z_{s}=m_{s}^{b} /\left(\sum_{h \in H} d^{h}+\sum_{b \in B} m_{s}^{b}\right), \bar{z}=\bar{m}^{b} /\left(\sum_{h \in H} \bar{d}^{h}+\sum_{b \in B} \bar{m}^{b}\right), z=d^{b} /\left(\sum_{b \in B} d^{b}+M^{G}\right)$, and $\pi_{s}^{b}=\Delta\left(6^{b}\right)$.

Note that since the banking sector is perfectly competitive loan repayments are made proportional to the credit issued by each commercial bank relative to the aggregate credit issued by the entire banking sector.

\section{Equilibrium}

We say that ${ }^{39}\left(n,\left(\sigma^{h}\right)_{h \in H},\left(\sigma^{b}\right)_{b \in B}\right)$ is a monetary equilibrium with commercial banks and default (MECBD) for the economy $E=\left\{\left(u^{h}, e^{h}, m^{h}\right)_{h \in H},\left(u^{b}, e^{b}\right)_{b \in B}, A, M^{G}, \mu^{G}, m^{G}, b^{G}, k, \lambda\right\}$

iff:

$$
p_{s l}=\frac{\left(\sum_{h \in H} b_{s l}^{h}+m_{s}^{G}\right)}{\sum_{h \in H} q_{s l}^{h}}, \quad \forall s \in S, l \in L
$$

Condition (i) shows that all commodity markets clear (or equivalently that price expectations are rational).

(ii) $1+\rho=\frac{\left(\sum_{b \in B} \mu^{b}+\mu^{G}\right)}{\sum_{b \in B}\left(d^{b}+M^{G}\right)}$;

Condition (ii) shows that the interbank credit market clears (or equivalently that interbank interest rate forecasts are rational).

(iii) $\quad 1+r_{s}=\frac{\sum_{h \in H} \mu_{s}^{h}}{\left(\sum_{h \in H} d_{s}^{h}+\sum_{b \in B} m_{s}^{b}\right)}, \quad \forall s \in S^{*}$;

\footnotetext{
${ }^{39}$ Recall that by assumption $p, \rho, r_{s} \bar{r}, \theta, R$ are different from 0 and $\infty$ in each component.
} 
(iiia) $1+\bar{r}=\frac{\sum_{h \in H}^{-\mu^{h}}}{\left(\sum_{h \in H} d^{h}+\sum_{b \in B}^{-b} m^{-b}\right)}$;

Condition (iii) shows that all short-term (long-term) credit markets clear (or equivalently, that predictions of long-term interest rates are rational).

$$
\theta_{j}=\frac{\left(\sum_{h \in H} b_{j}^{h}+\sum_{b \in B} b_{j}^{b}\right)}{\left(\sum_{h \in H} q_{j}^{h}+\sum_{b \in B} q_{j}^{b}\right)}, \quad \forall j \in J
$$

Condition (iv) shows that asset markets clear (or equivalently, asset price expectations are rational).

$$
\sum_{h \in H} u_{b}^{h}=1, \forall \mathrm{b} \in \mathrm{B}
$$

Condition (v) shows that the equity market for the bank ownership clears (or equivalently bank equity shareholding expectations are rational).

$$
R_{s j}= \begin{cases}\frac{\sum_{h \in H \cup B}\left[v_{s j}^{h} p_{s} q_{j}^{h} A^{j}\right]}{\sum_{h \in H \cup B}\left[p_{j} q_{j}^{h} A^{j}\right]} \quad, \text { if } \sum_{h \in H \cup B}\left[p_{j} q_{j}^{h} A^{j}\right]>0 & ; \forall s \in S, \quad j \in J . \\ \text { arbitrary } & , \text { if } \sum_{h \in H \cup B}\left[p_{j} q_{j}^{h} A^{j}\right]=0\end{cases}
$$

Condition(vi) shows that each asset buyer is correct in his expectation about the fraction of assets that will be delivered to him. ${ }^{40}$

\footnotetext{
${ }^{40}$ Rates of delivery do not depend on anything that agents do themselves. Every agent receives the same rate of delivery. This is in accordance with the spirit of mass anonymous capital and credit markets. Otherwise, I would need to consider complicated strategic consequences, which unnecessarily complicate the model. However, even though the model does not include interpersonal moral hazard problems it deals with moral hazard in the aggregate.
} 


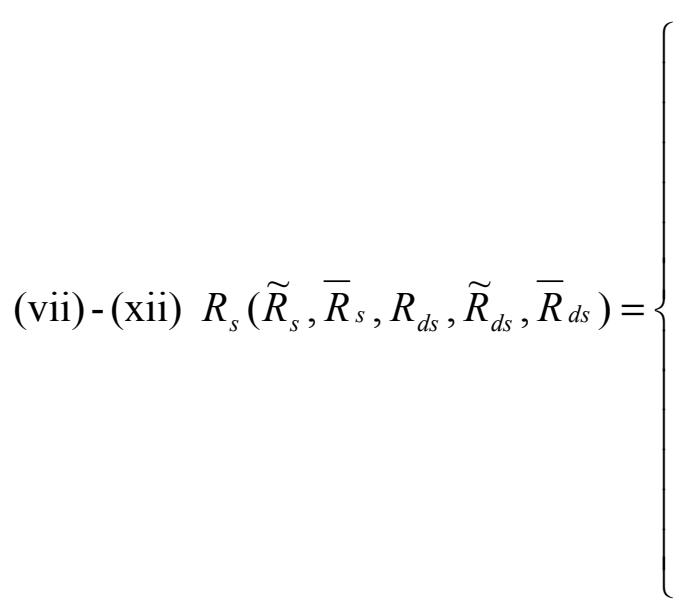

$$
\begin{gathered}
\sum_{h \in H \cup B}\left[v_{s}^{h} \mu_{s}^{h}\left(\mu^{h}, \bar{\mu}^{h}, d^{h}(1+\rho), \bar{d}^{h}(1+\bar{r}), d_{s}^{h}\left(1+r_{s}\right)\right)\right] \\
\sum_{h \in H \cup B}\left[\mu_{s}^{h}\left(\mu^{h}, \bar{\mu}^{h}, d^{h}(1+\rho), \bar{d}^{h}(1+\bar{r}), d_{s}^{h}\left(1+r_{s}\right)\right)\right] \\
\quad \text { if } \sum_{h \in H \cup B}\left[\mu_{s}^{h}\left(\mu^{h}, \bar{\mu}^{h}, d^{h}(1+\rho), \bar{d}^{h}(1+\bar{r}), d_{s}^{h}\left(1+r_{s}\right)\right)\right]>0 \\
\text { arbitrary } \quad, \quad \text { if } \sum_{h \in H \cup B}\left[\mu_{s}^{h}\left(\mu^{h}, \bar{\mu}^{h}, d^{h}(1+\rho), \bar{d}^{h}(1+\bar{r}), d_{s}^{h}\left(1+r_{s}\right)\right)\right]=0 .
\end{gathered}
$$

Conditions (vii)-(xii) show that the Central Bank and commercial banks are correct in their expectations about the fraction of loans that will be delivered to them. Similarly, investors and commercial banks are correct ion their expectations about the fraction of deposits and interest rate payments that will be delivered to them.

$$
\text { (a) } \sigma^{h} \in \underset{\sigma^{h} \in B^{h}(\eta)}{\operatorname{Arg} \max } \quad \Pi^{h}\left(x^{h}\right)
$$

(xiii) and

$$
\text { (b) } \sigma^{b} \in \underset{\sigma^{b} \in B^{b}(\eta)}{\operatorname{Arg} \max } \quad \Pi^{b}\left(\pi^{b}\right) \text {. }
$$

Condition (xiii) shows that all agents optimise.

In sum, all markets clear and agents optimise given their budget sets. These are the defining properties of a competitive equilibrium.

If a Monetary Equilibrium with Commercial Banks and Default (MECBD) exists, then default and financial instability are established as equilibrium phenomena that arise in a standard equilibrium framework. Note, also that fiat money has positive value in a finite horizon economy (for an extensive discussion on this see, Dubey and Geanakoplos [20], Grandmont [25], and Hahn [35] who posed initially this problem). Government and regulator actions are exogenously fixed and are not deduced from optimising behaviour. Finally, no attempt is made to derive endogenously which assets will be traded in equilibrium in order to "endogenise" market incompleteness.

Conditions (vi)-(xii) ensure that expected deliveries of assets, loans and deposits are equal to realised deliveries in equilibrium. However, the specification of expectations for inactive markets is arbitrary. Thus, the model does not rule out trivial equilibria in which there is no trade. There are two ways around this case (i.e., exclude trivial equilibria ${ }^{41}$ ) in order to allow for comparative statics and policy analysis. The first has been introduced by Dubey and Shubik [23] and adds and external agent that always supplies the asset and loan market with a minimal amount $\varepsilon$ and never abrogates his contractual obligation. The second has been suggested in Dubey, Geanakoplos and Shubik [22] and

\footnotetext{
${ }^{41}$ Even though, the examination of trivial equilibria merits further study whenever one tries to study financial innovation and endogenous generation of incomplete asset structures.
} 
offers an equilibrium refinement by forbidding "overly pessimistic" expectations thus guaranteeing full delivery of small promises. I adopt the first way and then let $\varepsilon \rightarrow 0$. It is more natural to allow for government intervention that establishes the functioning of the markets rather than fixing expectations and so precluding potentially interesting phenomena of co-ordination failures and possibly discontinuous expectations in certain regimes of minimal trading. In addition, different expectation specifications may generate different prices and allocations. Finally, as can be seen from the proof the two methods are technically equivalent.

Hereafter, I will assume in (vi)-(xii):

Inactive Markets Hypothesis: Whenever credit or asset markets are inactive (i.e., asset supply, credit extension or deposits are 0) the corresponding rates of delivery are set equal to 1 .

\section{Money Demand, Quantity Theory of Money and the Term Structure of Interest Rates}

At each meeting of the market, money is exchanged for another instrument, which can be either commodities or assets or bonds. It is customary to regard such market exchanges as the interaction of demand and supply for the other instrument. But logically speaking, one might just as well speak of each of these exchanges as the interaction of demand and supply for money. The price of money at a moment in time depends on the instrument against which it trades at that moment, as does the reason for the demand. When the other instrument is a commodity, the price of money is the inverse of commodity prices. When it is a short-term bond, the price of money is the short-term interest rate $\left(1+r_{s}\right)$ and so on.

Money differs from other instruments in that it is never wanted in and of itself, but only so that it can be exchanged later for another instrument, or to pay back a debt. The demand for money, thus, always depends on the need for transactions. When these transactions are a long way off, I can speak of the store of value demand for money. In this model with uncertainty, I could speak of speculative and precautionary demands for money.

When the short-term bonds are sold for money, I speak of the transactions demand for money. The higher the interest rate, the fewer the transactions will be desired (and presumably the higher the money value of sales desired), and given the same interest rate the greater will be the demand for money. When long-term bonds are sold for money, the desire for money is often a desire to transfer wealth from the future to the present. In this case the demand for money will depend on the difference between the long-term nominal rate and the rate of inflation, that is on the real rate of interest. Finally the sale of commodities at date 0 , beyond what is necessary to repay debts at the end of date 0 , is motivated by a wish to transfer wealth forward. That source of demand for money is adversely affected by higher inflation.

There is also the precautionary demand for money. If investors expect higher interest rates in the future either due to credit contraction by commercial banks or contractionary monetary policy then they will borrow in the long-term credit market in period 0 . Alternatively, they would increase the sale of commodities in the first period. This activity would exercise a downward pressure on prices and will further increase $\bar{r}$. Moreover, there is also a speculative demand for money by inventorying money from period 0 to 1 . This is tantamount to carrying an asset (i.e., speculative cash balances) that compete with the rest of the assets. In principle, all the hypotheses of the term structure of interest rates are accommodated. Namely, when monetary policy is neutral the expectation hypothesis prevails whereas when it is non-neutral and liquidity constraints are binding then the 
Hicksian liquidity preference is present as well. Thus, we see that the standard Hicksian IS/LM determinants of money demand, namely interest rates and income, are at work in the model.

Nevertheless, it is also easy to see that with our simple specification of the economy, if all the interest rates are positive, then all the money will be spent in each $s \in S$ in the commodity markets. An investor, or a commercial bank, which has cash that he does not wish to spend it will not hold it idle, but he will lend it out to somebody who will spend it. However, this is not the case at $s=0$, since, because of the uncertainty and incomplete markets, investors will spend their cash also in the asset markets and may hold some precautionary reserves.

QUANTITY THEORY OF MONEY PROPOSITION: In a MECB, if $\rho>0$ then the aggregate income at $s \in S$, namely the value of all commodities sales is equal to the total credit provided by commercial banks plus asset payoff liquidity. At $s=0$, aggregate income equals the total central bank money supply plus deposits in the interbank credit market minus expenditures in the asset and equity markets, precautionary reserves and bank profits.

$$
\sum_{h \in H} \sum_{l \in L} p_{s l} q_{s l}^{h}=\sum_{b \in B} m_{s}^{b}+\sum_{h \in H \cup B} \sum_{j \in J} v_{j}^{h} p_{s} q_{j}^{h} A^{j}+\Delta\left(4^{h}\right) \quad, \forall s \in S
$$

For $s=0$,

$$
\sum_{h \in H} \sum_{l \in L} p_{0 l} q_{0 l}^{h}=M^{G}+\sum_{b \in B} d^{b}-\sum_{h \in H \cup B} b_{j}^{h}-\sum_{h \in H} \sum_{b \in B} u_{b}^{h}-\Delta\left(4^{h}\right)-\pi_{0}^{b} .
$$

It follows from the foregoing that if all interest rates are positive, then in equilibrium the quantity theory of money must hold, with velocity of money fixed at one. At any moment the stock of money will be equal to the value of nominal income, as we have defined it. Given the level of the real economic activity, price levels will move in the same direction as the stock of money (as more money chases the same goods). Yet, as I have been at pains to point out, this is no crude quantity theory in which the demand for money is independent of interest rates; quite the opposite is the case. For example, the "real" velocity of money, that is how many real transactions can be moved by money per unit time, is endogenous. I also hasten to add that in richer versions of the model, in which there are other durable assets and perhaps transaction costs from depositing and withdrawing money from the bank, money might be held without being spent, depending on interest rates and income, or else spent on assets (which would not count as aggregate income).

In equilibrium, the quantity of economic activity, by which I mean the quantity of real goods traded in a period, is endogenous. By contrast, in the model of Lucas and his followers ([42],[43],[44]), the amount of real economic activity is exogenously specified by the requirement that each agent sells the whole of his endowment in each period. A corollary of the quantity theory of money in our model is that, all others being equal, increases in trading activity in state $s$, due perhaps to more productivity or lower interest rates, will result in lower state $s$ price levels, given the same money supply in state $s$. Similarly, the volume of trade in the asset markets affects the prices and has second order effects on the inflation rate.

The model can encompass several monetary theories, if I superimpose structural assumptions and restrictions. However, even at this level of generality, several useful results can be stated. 
PROPOSITION 1: At any $M E C B D, \bar{r}, r_{s}, \geq 0 \quad \forall s \in S^{*}$ and $\bar{r} \geq r_{0} \geq 0$.

PROPOSITION 2: At any $M E C B D, \rho \geq r_{s}, \bar{r} \quad \forall s \in S *$

This proposition holds because the ex ante interest rates are considered and they do not incorporate their respective default premia. Thus, borrowing rates have to be higher than lending rates to preclude arbitrage opportunities. It also emphasises the power of the monetary authorities to control the interest rates and influence the term structure of the economy.

The money injected into the economy by the government, and the money endowments are exogenous in my model. In equilibrium, for all states $s \in S$, the money flowing out of the system in interest payments to the commercial banking sector, and consequently to the central bank appropriately adjusted by the capital-adequacy ratio and the realised rates of delivery, must equal the money flowing into the economy. Otherwise, agents would be stuck in the last period with worthless paper, and the value of money would be zero (which is ruled out in MECBD). However, at $s=0$, the supply of money is endogenous and is determined by the optimising behaviour of investors and commercial banks.

TERM STRUCTURE OF INTEREST RATES PROPOSITION: At any $M E C B D, \forall s \in S$,

$\left[\sum_{b \in B}\left(m_{0}^{b} r_{0}+m_{s}^{b} r_{s}+\bar{m}^{b} \bar{r}\right)\right]=\sum_{h \in H}\left(m_{0}^{h}+m_{s}^{h}\right)\left(\frac{1}{v_{s}^{h}}\right)+\sum_{b \in B}\left(e_{0}^{b}+e_{s}^{b}\right)\left(\frac{1}{v_{s}^{b}}\right)$

(The analogous equation holds with weak inequality for $s=0$. )

The term structure equation is now affected by both liquidity provision by banks and default by households and banks.In the one period case, the interest rate can be specified a priori, independent of the "real" data of the economy. But in a multiperiod setting there are two degrees of freedom since there are $S$ equations and $S+2$ interest rates to be determined in equilibrium. Therefore, the term structure of interest rates is endogenously determined at $s=0$, and depends on the real data of the economy and is subject to policy interventions. The exception is where all government deficit spending is zero, in which case all interest rates are zero for all states $s \in S^{*}$.

Finally, since the model has an integral monetary sector, the interest rates determined in equilibrium are in nominal terms. Thus, they depend both on the real interest rates and the prevailing inflation rate. I summarise this intuition in the following proposition.

FISHER EFFECT PROPOSITION: Suppose that for some $h \in H, b_{0 l}^{h}$ and $b_{s l}^{h}>0$, for $l \in L$ and $s \in S$. Suppose, further that $h$ has some money left over the moment that the long loan comes due at $s \in S$. Then, at a $M E C B D$,

$$
(1+\bar{r})=\left(\frac{\frac{\partial u^{h}(x)}{\partial x_{0 l}}}{\frac{\partial u^{h}(x)}{\partial x_{s l}}}\right) \cdot\left(\frac{p_{s l}}{p_{0 l}}\right)
$$


Taking the logarithm of both sides and interpreting loosely, this says that the nominal rate of interest is equal to the real rate of interest plus the (expected) rate of inflation.

\section{Asset Pricing}

Positive interest rates and the liquidity based market transactions introduce a "price wedge" whose size depends on period zero interest rates. The "price wedge" manifests itself both in the commodity and the asset markets. ${ }^{42}$ The complication that positive interest rates introduce is the failure of the exact linear pricing rule of assets. Recall, that in standard finance theory, if an asset's payoffs is a linear combination of the payoffs of other assets then its price is a linear combination of the prices of the other assets. However, the transaction cost for the purchase of goods and assets manifested through the interest rate, generates an approximate relationship that bounds the asset prices.

PROPOSITION 3: Suppose that $A^{j}=\lambda_{1} A^{1}-\lambda_{2} A^{2}$ and $\lambda_{1}, \lambda_{2} \geq 0$. If asset $j \in J$ is traded at a $M E C B D$ then

$$
\lambda_{1} \theta_{1}-\left(1+r_{0}\right) \lambda_{2} \theta_{2} \leq \theta_{j} \leq \lambda_{1} \theta_{1}-\left(\frac{1}{1+r_{0}}\right) \lambda_{2} \theta_{2}
$$

Note that the linearity principle obtains only if all the private monetary endowments, and initial capital condition of commercial banks are zero. Moreover, the bankruptcy penalties should be such that they preclude bankruptcy altogether. Thus, interest rates will all be zero and linear pricing will obtain. Finally, note that if $A^{j}$ is a positive linear combination of $A^{1}$ and $A^{2}$ then exact linear pricing holds. This occurs because the replicating portfolio consists of either short or long positions and thus the "price wedge" does not matter. It does have real (price) effects only when the investor sells in one transaction whereas he borrows to purchase the asset in the other and so incurs the interest rate payment. Thus, in transactions-based models with explicit liquidity constraints, investors preferences interact through the markets with asset payoffs and determine asset prices unlike models in which liquidity and money are absent and the martingale pricing theorem obtains. In sum, whenever financial stability issues arise the conventional finance models based on the classical Arrow-Debreu framework are not suitable to address their effects. Liquidity and default are the cornerstones of financial instability.

42 From the first order conditions of maximisation, suppose that for $l, k \in L$ and $b_{s l}^{h}, q_{s k}^{h}>0$, for some $h \in H$, $s \in S^{*}$.

Then, at a MECBD, $\frac{\left(\frac{\partial u^{h}(x)}{\partial x_{s l}}\right)}{\left(\frac{\partial u^{h}(x)}{\partial x_{l k}}\right)}=\frac{p_{s l}\left(1+r_{0}\right)}{p_{s k}}$, provided $r_{0}>0$. 


\section{Orderly Function of Markets: Existence}

Economic agents in our model are not required to trade. They always have the option to consume their own endowment in each state. Thus, there is no guarantee that they will demand money from any of the credit markets available at the economy. Moreover, if there is no demand for credit from investors, then it becomes ambiguous whether the interbank credit market will be active altogether. And if there is no demand for liquidity in the economy then the asset market, in turn, will become inactive too. Indeed, in such a scenario, money will not have positive value and the nominal sector of the economy (monetary and financial) may be inactive and the corresponding markets may collapse.

Lucas circumvents the problem by forcing each agent to offer for sale his entire endowment, and then buy it back using money even if he himself wants to consume it. So, agents need money and liquidity by assumption since they can not even consume their own endowment without it. The positive value of money is not an artifact of the infinite horizon but an outcome of the transaction mechanism postulated in the model (both cash-in-advance and mandatory sale of endowment). Thus positive trade in equilibrium is not a result but an exogenous datum of the model.

Although the assumption that each agent must sell all of his endowment seems innocuous, I will show that when combined with the "representative agent" assumption that all agents have the same preferences, it implies monetary policy neutrality.

This is so because lack of heterogeneity and forced sale of endowments imposes the classical dichotomy on the model and generates a trivial version of the quantity theory of money. This is in stark contrast with my model where the validity of the classical dichotomy and the resulting quantity theory is determined endogenously in equilibrium, as shown by the existence argument, the propositions on the term structure of interest rates and the quantity theory of money.

When some monetary endowments are positive, including the commercial banks' initial capital endowments, then the term structure proposition shows that some interest rates must be positive. Otherwise, agents will be left at the end of period $l$ with worthless paper money, and then by rational expectations and backward induction, the Hahn argument [34] would obtain; money will have zero value. When interest rates are positive, agents will be willing to give up commodities even in period 1 to repay fully (or in part if they default) the loans they took from the banks for precautionary and speculative purposes as well as for transaction purposes.

However, when interest rates are positive (including the interbank interest rate) agents may not be willing to borrow from commercial banks (respectively commercial banks from the Central Bank). By borrowing $1 £$ from the bank an agent can buy $1 £$ worth of commodities. But, he subsequently must sell $(1+r) £>1 £$ worth of commodities in order to repay his loan. The agent will only agree to such a deal if the benefit of the increased utility from the additional commodities exceeds the utility loss from the commodities that he sells to repay his loan. Similarly, the commercial banks will incur a decrease in "profitability" equal to $(1+\rho) £$ for every dollar they borrow in the interbank market whereas they will receive, if they extend the full amount of the loan, $\left(1+r_{s}\right) £(\operatorname{or}(1+\bar{r}) £)$. Thus, the transaction must be sufficiently profitable to undertake it.

I am, thus, naturally led to make a crucial assumption that there are sufficient gains to trade available to agents, to justify voluntary interest rate payments on grounds of rational behaviour. The formal description of the necessary gains to trade turns out to be surprisingly simple. Before providing the characterisation of that assumption, it should be noted that dropping the artificial sell-all assumption of Lucas, it requires imposing minimum heterogeneity among agents, so that they want to trade. The 
simplest heterogeneity is intraperiod heterogeneity in endowments, so I also require $L \geq 2$. Therefore, my model is different from that of Lucas, who postulated $H=L=1$.

Debreu [18] suggested that an allocation $\chi^{h} \in R_{+}^{S^{*} L}$ for each $h \in J \subset H$ is not $\delta$-Pareto efficient for $h \in J$, if it is possible to costlessly reallocate the commodity bundle $(1-\delta) \chi$ among those agents and make them all better off than they were at the original allocation. He called $\delta$ the coefficient of resource utilisation and interpreted it as a measure of how far a given allocation is from Pareto optimality. Dubey and Geanakoplos [20] proposed that an allocation permits at least $\delta$ gains to trade if starting from that allocation, it is possible to make everybody better off in $J \subset H$ by transferring commodities, even though a fraction $\delta$ of the original bundle is lost. Following, Dubey and Geanakoplos [20], [21] who first introduced the gains to trade hypothesis, and Geanakoplos and Tsomocos [28] who used it in a related model, I modify the definition and the hypothesis to the present framework. Debreu threw out a fraction $\delta$ of the original bundle, but allowed for costless transfers. I keep instead, the whole of the original bundle, but throw out a fraction $\delta$ of every transfer.

The crucial insight of the gains-to-trade definition is that even if transactions are costly the higher utility that extra consumption would entail still makes them possible. This intuition can be stated formally in the following definition.

\section{Definition:}

Let $\left(\chi^{h}, \pi^{b}\right) \in R_{+}^{S^{*} \times(L+1)} \quad \forall h \in H, b \in B . \quad \forall \delta>0$, we will say that

$\left(\chi^{1}, \ldots, \chi^{h} ; \pi^{1}, \ldots \pi^{b}\right) \in\left(R_{+}^{S^{*} \times L}\right)^{H} \times R_{+}^{S^{*} \times B}$ permits at least $\delta$-gains-to-trade in state $s$ if there exist trades $\tau^{1}, \ldots, \tau^{H} ; \tau^{1}, \ldots, \tau^{B} \quad$ in $\quad R^{L+1} \quad$ such that

1. $\sum_{h \in H} \tau^{h}+\sum_{b \in B} \tau^{B}=0$

2. (a) $\chi_{s}^{h}+\tau^{h} \in R_{+}^{L}, \quad \forall h \in H$

(b) $\hat{\pi}_{s}^{b}+\tau^{B} \in R, \quad \forall b \in B$

3. (a) $u^{h}\left(\bar{x}^{h}\right)>u^{h}\left(x^{h}\right), \quad \forall h \in H$

(b) $u^{b}\left(\bar{\pi}^{b}\right)>u^{b}\left(\pi^{b}\right) \quad$ where,

$$
\begin{aligned}
& \bar{x}_{t l}^{h}=\left\{\begin{array}{l}
\chi_{t l}^{h}, \quad t \in S^{*} \backslash\{s\} \\
\chi_{t l}^{h}+\min \left\{\tau_{l}^{h}, \tau_{l}^{h} /(1+\delta)\right\} \quad \text { for } l \in L \text { and } t=s
\end{array}\right\} \\
& \bar{\pi}_{t}^{b}=\left\{\begin{array}{l}
\pi_{t}^{b}, t \in S^{*} \backslash\{s\} \\
\pi_{t}^{b}+\min \left\{\tau^{b}, \tau^{b} /(1+\delta\} \quad \text { for } t=s\right.
\end{array}\right\}
\end{aligned}
$$


Note that when $\delta>0, \bar{x}_{l}^{h}<\chi_{t l}^{h}+\tau_{l}^{h}$, if $\tau_{l}^{h}>0$ and $\bar{x}_{t l}^{h}=x_{t l}^{h}+\tau_{l}^{h} \quad$ if $\tau_{l}^{h} \leq 0$.

Also, $\bar{\pi}_{t}^{b}<\pi_{t}^{b}+\tau^{b}$, if $\tau^{b}>0$ and $\bar{\pi}_{t}^{b}+\tau^{b}$, if $\tau^{b} \leq 0$

Formally, the hypothesis I impose on the economy for sufficient gains to trade is:

G to T: $\forall s \in S$, the initial endowment $\left(e^{h}, e^{b}\right)_{h \in H, b \in B}$ permits at least $\delta_{s^{-}}$gain to trade in state $s$, where

$$
\delta_{S}=\frac{\sum_{h \in H} m_{0}^{h}+\sum_{h \in H} m_{s}^{h}+\sum_{b \in B} e_{0}^{b}+\sum_{b \in B} e_{s}^{b}}{M^{G}} .
$$

The value of this ratio imposes an upper bound on the transaction costs incurred by agents from interest rate payments as can be seen from Proposition 2.

Condition (G to $\mathrm{T}$ ) needs to be valid $\forall s \in S$ but not for $s=0$. Note that gains from trade should be present in the banking sector even though commercial banks do not consume. But since they are mutually owned and are liquidated at the end of period 1, rational agents expect these proceeds and incorporate them in the maximisation problem as can be seen from their budget constraint $\left(\left(9^{h}\right)\right.$ of 3.1). Also ( $\mathrm{G}$ to $\mathrm{T}$ ) precludes the case where $L=1, \forall s \in S^{*}$. Moreover, if the initial endowment is not Pareto optimal $\forall \mathrm{s} \in \mathrm{S}$, then holding all other government actions fixed as I vary $M^{G} \rightarrow \infty$, (G to T) is automatically satisfied. ${ }^{43}$ The following theorem is proved in the Appendix.

THEOREM 1: If in the economy $E=\left\{\left(u^{h}, e^{h}, m^{h}\right)_{h \in H},\left(u^{b}, e^{b}\right)_{b \in B}, A, M^{G}, \mu^{G}, m^{G}, b^{G}, \kappa, \lambda\right\}$,

(1) Gains to Trade and Inactive Markets Hypotheses hold,

(2) $M^{G}>0$,

(3) $\forall s \in S, \sum_{h \in H} m_{s}^{h}+\sum_{b e B} e_{s}^{b}>0$ and

(4) $\lambda>>0, \forall h \in H, b \in B$

then a MECBD exists.

The proof of this theorem resolves the Hahn problem and also the non-existence example of Hart [36]. Positive interest rates and bankruptcy penalties compactify the choice space by binding the potential transactions in the asset markets. Radner [50], instead, imposed artificial bounds on asset trades to show existence. The proof of the theorem also indicates that as the aggregate "outside" money becomes large then the necessary gains to trade for existence becomes arbitrarily large. Therefore as "outside" money grows, prices eventually rise, converging rapidly to infinity. When the ratio of outside to inside money becomes high enough so that equilibrium is unsustainable, hyperinflation occurs and trade collapses.

${ }^{43}$ Alternatively, if $\sum_{h \in H} m_{s}^{h}=0$ and $\sum_{b \in B} e^{b}=0, \forall \mathrm{s} \in \mathrm{S}^{*}$ then $\mathrm{G}$ to $\mathrm{T}$ is automatically satisfied. See Shubik and Tsomocos [55], for the argument of this case in a related model. 
The main argument of the proof is that the monetary authority backs the fiat money present in the economy and gives it real value. By this is meant that "money is an institutionalised symbol of trust." "The government compels the acceptance of money as a final discharge of debt. Investors use this "government-backed" money because the benefit it gives them is greater than the interest rate loss. The interest rate can be thought of as the tax levied by the government for the supply of "trust" and the "system" that it establishes to safeguard trade in assets and commodities. This argument does not rest only on the cash in advance constraint but also on the presence of the government, standing ready to recoup loans, and the potential gains from trade. It is this triplet that guarantees existence and positive value of fiat money in the finite horizon.

\section{Financial Instability, Contagion and Systemic Risk}

\subsection{Financial Instability: Concepts and Definitions}

Numerous authors have tackled financial stability and at one level the term seems to be a familiar one both from a theoretical as well as a practical viewpoint. However, very few attempts have been made to formally define and characterise it in an analytically meaningful way. Academics and policy-makers have offered various definitions. ${ }^{45}$ For example, Andrew Crockett [16] argues that "financial stability (refers) to the stability of the key institutions and markets that go to make up the financial system...stability requires (i) that the key institutions in the financial system are stable, in that there is a high degree of confidence that they continue to meet their contractual obligations without interruption or outside assistance; and (ii) that the key markets are stable, in that participants can confidently transact in them at prices that reflect fundamental forces and that do not vary substantially over short periods when there have been no changes in fundamentals". Mishkin [45] offers a more "information based" definition. "Financial instability occurs when shocks to the financial system interfere with information flows so that the financial system can no longer do its job of channelling funds to those with productive investment opportunities".

An alternative definition of financial instability that encompasses the basic features of the previous definitions is proposed, however, it is, I think, more analytically tractable in the context of a general equilibrium model.

\section{Definition:}

When substantial default of a "number" of households and banks (i.e., a liquidity "crisis"), without necessarily becoming bankrupt, occurs and the aggregate profitability of the banking sector decreases significantly (i.e., a banking "crisis").

$$
\begin{aligned}
& \text { Formally, a } \quad \operatorname{MECBD} \quad\left(n,\left(\sigma^{h}\right)_{h \in H},\left(\sigma^{b}\right)_{b \in B}\right) \quad \text { is financially fragile whenever } \\
& D_{s \omega}^{h^{*}}, D_{s \omega}^{b^{*}} \geq \overline{\mathrm{D}}, \sum_{b \in B} \pi_{s}^{b} \leq \bar{\Pi}, \text { for }\left|H^{*}\right|+\left|B^{*}\right| \geq \bar{Z} \text {, and } s \in S^{*} \text { where } \bar{Z} \in(0,|H| \cup|B|] \text { and } \bar{\Pi}, \bar{D} \in R_{++} . \\
& 46
\end{aligned}
$$

Thus, financial instability is characterised by both liquidity shortage and banking sector vulnerability. Moreover, it is allowed that the authorities (government and/or the Central Bank) have

\footnotetext{
${ }^{44}$ Shubik [46].

${ }^{45}$ A survey of these definitions and extensive discussion can be found in Bank for International Settlements [5].

$46 \Pi$ (D) may be exogenously fixed or constructed as a weighted average of expected banking profits (defaults).

Alternatively, one can just compare profitability (default) across different equilibria.
} 
the liberty to determine the threshold, which is commensurate with the outset of a financially unstable environment. Also note that this definition hinges upon the welfare of the economy and its distributional consequences, when one works with explicitly multi-agent models. The standard techniques and the well-known theorems of equilibrium theory can be readily applied. Equilibrium analysis is also amenable to comparative statics, for example, by varying capital requirement rules one can determine the expected default and the welfare effects of a crisis.

A natural question that may be raised is why either one of the conditions is not sufficient to constitute a financially unstable regime. Besides the empirical evidence provided in the introduction, increased default without reduced profitability might be an indicator of increased volatility and risktaking without necessarily leading to financial instability. On the other hand, lower bank profitability without increased default might be an indicator of a recession in the real economy and not of financial vulnerability. It is the combination of both conditions that destabilises the financial system and may produce financial crises.

The following regimes are distinguished:

Liquidity "crisis": A situation in which there exists substantial default of a 'number' of defaults (not necessarily bankruptcy and closure) both in the investor/household as well as the commercial banking sector.

Banking "crisis": Together with substantial default of a "number' of commercial banks, it is required that the profitability of the banking sector as a whole decreases significantly via interbank linkages.

Recession: In the context of an equilibrium model, a recession entails welfare losses by the aggregate investor/household sector.

This definition is, I think, flexible enough to encompass most of the recent episodes of financial instability. For example, the Japanese crisis can be thought of as a bona fide phenomenon of the Keynesian liquidity trap. The Mexican crisis of the early 1990s is a classic example of liquidity and banking crisis. The late 1990s east Asian crisis was characterised by a banking crisis and economic recession as well as extensive default. Finally, the Russian crisis, the Texas Banking crisis, and the U.S. Stock Market crash of 1987 conformed to the characterisation of a financially unstable regime generated by liquidity shortages, extensive default and declines in bank profitability.

In conclusion, the information-based definition of Mishkin and the institutionally oriented one offered by Crockett arguably encompass crucial aspects of financial instability, however, they are distanced from the main reason that policy makers focus on instability, namely its welfare and distributional effects. In other words, their definitions highlight the inefficiency that a financially unstable regime generates but they are too general to be applicable for policy analysis. In addition, they do not address structural features (liquidity shortages and extensive default) that result in reduced bank profitability. Finally, widespread default and pronounced decrease in banks profitability eventually impairs markets and trade collapses altogether. Thus, a systemic financial crisis of the economy can be reinterpreted as a case of equilibrium non-existence.

\subsection{Liquidity Trap}

An extreme case of financial instability is the well-known liquidity trap. An economy manifests a liquidity trap whenever financial instability is coupled with monetary policy ineffectiveness. The Keynesian liquidity trap describes a situation in which monetary policy would not affect the nominal 
variables of the economy because consumers simply hold extra real money balances for speculative purposes. Given that interest rates are sufficiently low and they expect them to go up in the future, thus they do not invest into assets like bonds whose value will decrease when interest rates rise. Various authors provide explanations and formalisations of the liquidity trap, e.g. Hicks [38], Tobin [55], Grandmout and Laroque [22], and Hool [39] among others, based on non-rational expectations.

Dubey and Geanakoplos [21] provide an alternative explanation based on the incompleteness of asset markets. As the money supply increases, investors spend most of their liquidity in the asset markets. Thus, the monetary expansion does not affect the real sector of the economy and prices remain bounded. So, in the economy, large amounts of money are inventoried from period 0 to 1 via transactions in the asset market. The increased trading activity in the asset market results from combining assets whose payoffs differ only slightly in order to hedge against risks that are not directly insurable by a marketed asset. Indeed, the liquidity trap occurs when the underlying economy does not possess equilibrium. ${ }^{47}$

In the present model the liquidity trap occurs via the same process. However, now commercial banks engage in large asset trades without changing the interest rates of the consumers' credit markets. When the government employs an expansionary monetary policy, commercial banks do not channel the increased liquidity to the consumer credit markets but the asset market, and therefore increased activity is observed in asset transactions. So, commodity prices remain relatively unaffected along with the interest rates of consumer credit markets.

The liquidity trap is observed in the interbank market and not in the rest of capital markets where trades are very large and prices naturally are affected. I summarise the previous argument in the following proposition. This is consistent with the intuition that it may be the case that the liquidity trap may occur in an isolated section of the capital markets and then impinges upon the rest of the nominal sector of the economy (e.g., Japan in the late 1990s). ${ }^{48}$

PROPOSITION 4: Suppose that the economy has a riskless asset $A_{s m}^{j}=(1, \ldots, 1)$, (i.e., monetary payoffs in every state are equal to one) and $A_{s l}^{j}=0, \forall s \in S^{*}$ and $l \in L$. Also consider the case in which the underlying economy has no GEI. Then as $M^{G} \rightarrow \infty$, then

$$
\begin{aligned}
& w_{s s}^{b}(\eta, \sigma) R_{s} m_{s}^{b}\left(1+r_{s}\right)+w_{s \overline{0}}^{b}(\eta, \sigma) \bar{R}_{s} \bar{m}^{b}(1+\bar{r})+\sum_{j \in J} w_{s j}^{b}(\eta, \sigma) R_{s j}\left(p_{s} A_{s}^{j}\right)\left(\frac{b_{j}^{b}}{\theta_{j}}\right)+w_{s 0^{*}}^{b} \widetilde{R}_{d s}(1+\rho) d^{b} \rightarrow \infty, \\
& \forall \mathrm{s} \in \mathrm{S}^{*}, \\
& w_{00}^{b}(\eta, \sigma) R_{0} m_{0}^{b}\left(1+r_{0}\right)+w_{0 \overline{0}}^{b}(\eta, \sigma) \bar{m}^{b}(1+\bar{r})+\sum_{j \in J} w_{0 j}^{b}(\eta, \sigma)\left(p_{s} A_{s}^{j}\right)\left(\frac{b_{j}^{b}}{\theta_{j}}\right)+w_{00^{*}}^{b}(\eta, \sigma)(1+\rho) d^{b} \rightarrow \infty,
\end{aligned}
$$

for $s=0$,

$$
M^{G} /\left\|p_{o l}\right\| \rightarrow \infty \text {, and }\left(\sum_{h \in H} q_{j}^{h}+\sum_{b \in B} q_{j}^{b}\right) \rightarrow \infty .
$$

Moreover, there exist

$\bar{D}$ and $\bar{\Pi}$ such that $D_{s \omega}^{h^{*}}, D_{s \omega}^{b^{*}}>\overline{\mathrm{D}}>0$ for some $b^{*} \in B, h^{*} \in H$, and $\sum_{b \in B} \pi_{s}^{b} \leq \bar{\Pi}$.

\footnotetext{
${ }^{47}$ The non-generic counterexample of GEI non-existence was first discovered by Hart [36].

${ }^{48}$ Charles Goodhart made this point to me and it seems that the model accommodates it
} 
Note that regulatory policy may "break" this liquidity trap by imposing harsh capital requirements (or very high $w_{j}^{\prime}$ s) and so, blocking excessive trading activity in the asset markets. Thus, extra liquidity will be available for credit extension and further gains to trade will be materialised by the households due to lower interest rates.

\subsection{Bank Runs}

Perhaps, one of the most noteworthy features of this definition is that it encompasses a wide spectrum of financially unstable regimes and treats the original result by Diamond and Dybvig as a special case. The situation that corresponds to default of the entire banking sector is tantamount to the Diamond-Dybvig inefficient outcome.

Diamond and Dybvig [19] in their seminal paper on bank runs provided a model in which, in an inefficient equilibrium, commercial banks are unable to meet their withdrawal requirements and investors withdraw their deposits prematurely. Thus, banks default and this situation are interpreted as a bank run. This situation emerges in this model, however, because of bank heterogeneity, intermediate situations where not all banks default or all depositors withdraw can also arise. Since default is pooled in the model, contagion occurs by the domino effect that default causes. For example, when $\mathrm{Mr}$ A defaults on $\mathrm{Mr} \mathrm{B}$, then $\mathrm{Mr} \mathrm{B}$ is unable to meet his obligation to $\mathrm{Mr} \mathrm{C}$ and so on. At the end, aggregate default is pooled and prorated among the participating agents and institutions in a market. Thus, one observes the contagious effects of adverse shocks to the economy and the mass anonymous nature of the market capturing the systemic risk involved in the case of default.

PROPOSITION 5: Suppose that at a MECBD $\lambda$ 's $<<\infty, M^{G}<<\infty$ and $\kappa \leq 1$. Further, suppose $q_{j}^{b}=0, \forall b \in B$. Also, there exists $s \in S^{*}$ such that $\sum_{h \in H} \mu_{s}^{h}>\sum_{h \in H} d_{s}^{h}$. Then there exists $b \in B$ such that $D_{s \omega}^{b}>0$ in $s$.

COROLLARY 1 (Diamond-Dybvig): If together with the assumptions of the previous proposition we have $u^{b}=u, \lambda_{s}^{b}=\lambda$ and $\sum_{h \in H} \mu_{s}^{h}>\sum_{h \in H} d_{s}^{h}, \forall s \in S^{*}$ and $b \in B$, then $D_{s \omega}^{b}>0, \forall b \in B$ and $s \in S^{*}$.

This corollary that captures the essence of the logic in the Diamond and Dybvig result highlights the special nature of their model and the importance of bank homogeneity. Moreover, all commercial banks are identical and default is pooled. Thus, all depositors rationally expect that the commercial banking sector will uniformly default on its obligations in all future states.

COROLLARY 2: Let the same assumptions of Corollary 1 hold and $k=1$. Then there exists $\overline{\lambda^{b}}$ such that $D_{s \omega}^{b}=0, \forall b \in B, \quad s \in S^{*}$. In addition, there exists $\bar{\lambda}^{h}$ such that $D_{s \omega}^{b}=0 \forall h \in H$.

Put differently, Corollary 2 underlines the importance of capital requirements for financial stability. Therefore, whenever credit is fully collateralised, the regulator guarantees future financial stability. But, there is a trade off between financial stability and efficiency since stricter capital requirements generate higher interest rates and thus reduce efficient trade and limit banks' risk taking behaviour. Thus, $\lambda$ 's, $\kappa^{\prime}$ s and monetary policy should be studied contemporaneously when optimal regulatory policy is designed. 


\subsection{Constrained Inefficiency}

Whenever markets are complete $M E C B D$ are efficient provided that all interest rates are zero, there is no bankruptcy and capital requirements are non binding. However, the question that naturally arises is whether, given market incompleteness, equilibria are constrained efficient. ${ }^{49}$ In view of active monetary and regulatory policy for crisis prevention and management, the answer is tantamount to justifying (or not) intervention. Constrained efficiency points in fixing the structure of the economy whereas constrained inefficiency suggests making adjustments within the structure and still improve the efficiency of the economy. In addition, the proposal of a New Basel Accord alters the capital requirements of banks and thus, the assessment of welfare consequences requires analysis of efficiency of $M E C B D$ under the dynamic adjustment of capital adequacy ratios. The short and medium term macroeconomic consequences of capital requirements point towards the examination of constrained efficiency of the economy. Indeed, Blum and Hellwig [10] in an IS-LM framework argue that capital adequacy regulation may reinforce macroeconomic fluctuations. The channel driving their result is increases in non-performing loans may lead banks to reduce credit extension and thus industry investment declines. However, one may wonder whether with diversified bank portfolios this result holds. It may very well be the case that banks switch their investment to other asset classes and firms search for funds in the asset markets. The following theorem indicates that the Blum and Hellwig is robust in this more general framework.

THEOREM 2 : Each MECBD $\left(n,\left(\sigma^{h}\right)_{h \in H},\left(\sigma^{b}\right)_{b \in B}\right)$ with $\lambda=+\infty$ and binding capital requirements (i.e., equations $\left(4^{b}\right)$ and $\left(7^{b}\right)$ ) is constrained inefficient among the allocations that are feasible and, given the period 0 optimal choices, it satisfies the budget constraints in all states of period 1 at the old equilibrium prices.

Indeed, Catarineu-Rabell and Tsomocos [49], in the context of a parameterised simulation, establish the optimal regulatory system (i.e., neutral, procyclical, countercyclical risk-weights) under different policy criteria (i.e., bank profit maximisation, welfare maximisation and default minimisation).

Therefore, if the government or the regulator intervened in period 0 through transfers, taxation or by modifying the capital requirements of the economy, it could Pareto improve (in the second best sense) the original equilibrium. Of course, such intervention presupposes the same period 1 equilibrium prices as in the old equilibrium. However, as the theorem asserts, such a Pareto improving intervention assumes no bankruptcy and binding capital requirements in the original equilibrium. When bankruptcy is allowed then a similar trade off exists as the one between severity of the bankruptcy code and efficiency ${ }^{50}$, but in this context the trade off is between regulatory policy and efficiency. The upshot of this discussion is that there exists optimal regulatory policy, which depends on the particular parameters of the economy. Thus, the dynamic adjustment of capital requirements needs context specific knowledge of the economy and most probably needs to be tailor made for each particular case. This is of great importance for the design of regulation.

\footnotetext{
${ }^{49}$ The pioneering paper on the subject of constrained inefficiency in incomplete markets with numeraire goods was written by Geanakoplos and Polemarchakis [26].

${ }^{50}$ See [22], for an example of this tradeoff. But no general theorem has yet been provided on this.
} 


\section{Determinacy and Non-Neutrality of Money and Regulatory Policy}

It will shown in section 10 that when government is not spending money and private stocks of money are very small (or zero) relative to bank money, MECBD is very close to GEI. In this section, I will show that as long as some private (or commercial banks') endowment of money is positive and MECBD is different from GEI, monetary and regulatory policies necessarily have real effects on consumption and the nominal variables of the economy. Similarly, government's money financed fiscal transfers to agents and commercial banks, irrespective to their distribution across the economy, also necessarily have real effects.

These non-neutrality conclusions are contrary to those derived by Lucas. The explanation rests on the inefficiency caused by the transactions mechanism of the model. Specifically, positive interest rates, even without default and production, generate different prices that sellers receive when they sell a commodity from the one a purchaser offers when he has borrowed money from commercial banks. For example, when the government eases monetary policy it facilitates borrowing by reducing interest rates and subsequently increases real activity or the volume of trade in the asset markets.

I show in Tsomocos [59] that MECBD are typically finite. Therefore, prices, interest rates and consumption are almost always determinate with respect to the data of the economy. This is in contrast with the real indeterminacy theorem of Geanakoplosn and Mas-Collel [27] and Balasko and Cass [4] but consistent with the determinacy theorem of Dubey and Geanakoplos [20]. The economic reason that determinacy, both real and nominal, obtains is that positive liquid wealth (i.e., outside money in the economy) anchors interest rates by the term structure of interest rates proposition and thus uniquely (locally) determines the rest of the variables in the model (i.e., prices, consumption, default). Indeed, the following theorem is shown in Tsomocos [59].

THEOREM 3: Let $\sum_{h \in H} m_{s}^{h}+\sum_{b \in B} e^{b}>0$ or $\lambda^{b}<\bar{\lambda}^{b}$ and $M^{G}>0$. Then for "generic" economies $E$ the set of $M E C B D$ is finite.

This theorem allows us to determine the impact of monetary and regulatory changes in the economy. The "no-money illusion" property easily follows:

PROPOSITION 6 (No Money illusion): A proportional increase of all

$\left(m_{s}^{h}\right)_{h \in H, s \in S^{*}},\left(e_{s}^{b}\right)_{b \in B, s \in S^{*}}$ and $\left(M^{G}, \mu^{G}, m^{G}, b^{G}\right)$ whereas the regulators' choices of $\kappa$ stay fixed while $\lambda$ 's scaled down proportionally, does not affect the real variables of MECBD.

I should note that such a change corresponds to a change in units and naturally should not lead to different equilibrium allocations. However, the regulator in practice is sluggish to adjust fully bankruptcy code and therefore such changes have real effects. ${ }^{52}$

Monetary policy usually changes the ratio of bank money to private endowments and initial endowments of commercial banks. In my model, I interpret monetary policy as a change in $M^{G}$ or $\mu^{G}$

\footnotetext{
${ }^{51}$ The term "generic" refers to a set of economies that is open, dense and of full measure.

${ }^{52}$ Only when $\lambda=\infty$, the change in units would surely have neutral effects.
} 
(i.e., open market operations). ${ }^{53}$ A change in $m^{G}$ (money financed fiscal transfer) or $b^{G}$ is interpreted as fiscal policy. Also regulatory policy refers to the regulator's instruments (i.e., $\lambda$ and $\kappa$ ). All of the above policy instruments typically have real effects since they change nominal interest rates, as can be seen from the term structure of interest rates proposition. As I explained in the introduction, higher nominal short rates, $r_{s}$, reduce the efficiency of intraperiod trade, and a higher nominal long rate $\bar{r}$ reduces the efficiency of the interperiod trade. Similarly, higher interbank interest rate reduces the efficiency of the economy since it results into higher interest rates by the actions of commercial banks in view of Proposition 2. The following proposition demonstrates the non-neutrality of monetary and regulatory policy in a case that can be analysed via the first order condition of equilibrium. $^{54}$

I define a MECBD to be indecomposable if for any $s \in S^{*}$ and any partition of goods into disjoint sets $L_{1}$ and $L_{2}$ there is some agent $h \in H$ who transacts in at least one commodity from each set in state $s \in S^{*}$.

PROPOSITION 7: Suppose that all $u^{h}$, $u^{b}$ are differentiable and $m_{s}^{h}, e_{s}^{b}>0$ or $\lambda^{b}<\bar{\lambda}^{b}$ and $\lambda^{h}<\bar{\lambda}^{h}$ for all $h \in H, \quad b \in B$ and $s \in S^{*}$. Suppose at an indecomposable MECBD at every $s \in S^{*}$ all $h \in H$ consume positive amounts of all goods $l \in L$ and that some $h \in H$ carries over money from period 0 to 1 . Then, any change by the government or the regulator (except the one described by Proposition 6) results into a different MECBD in which for some $h \in H$ consumption is different.

Since increases in the stock of bank money, roughly speaking, (i.e., expansionary monetary policy) ultimately move the economy closer to a competitive equilibrium, and hence closer to Pareto efficiency, one question is why does not the government drastically increase this expansion? I present three explanations.

First, there is a political reason. Expansionary open market operations increase the effective money supply causing prices to rise. (Rich) agents who own money, or money denominated assets, will find their real wealth reduced.

Second, the government doesn't really have the freedom to increase the bank money while leaving the private endowments of money fixed. As I have said earlier, much of the private endowment of money is due to receipts from government expenditures on salaries for government workers. All of these rise as the price level rises (e.g. indexation of wages and pensions during inflationary times).

Third, increasing $M^{G}$ probably would make agents think that the government was also going to increase $M^{G}$ in the future. If agents thought the latter increase might be bigger than the former, then they would anticipate an inflation, which would raise the long rate $\bar{r}$ making equilibrium less efficient.

Finally, I remark that the effect of market prices, lower interest rates and subsequent increased trading activity is tantamount to Keynesian monetary policy whereas fiscal policy will raise prices

\footnotetext{
${ }^{53}$ Alternatively, I could have allowed for interest rate targeting letting money supply to adjust in equilibrium. The two approaches are equivalent since market clearing in the credit markets has one degree of freedom with respect to government policy. Thus, the government may set either money supply or interest rates but not both.

54 The general argument of monetary and regulatory policy non-neutrality is presented in Tsomocos [59] where it is shown that typically regulatory and monetary changes have non-neutral effects.
} 
and possibly inflation and increase interest rates. This in turn reduces trading activity (crowding out) which is tantamount to Keynesian fiscal policy.

\section{Monetary Equilibrium with Commercial Banks and Default (MECB) vs. General Equilibrium with Incomplete Markets (GEI) and General Equilibrium (GE)}

Recall, $\left(p, \pi\left(\chi^{h}, \varphi^{h}\right)_{h \in H}\right)$ is a GEI for the underlying economy

$\mathrm{E}=\left(\left(u^{h}, e^{h}\right)_{h \in H}, A\right)$ iff:

(xi) $\quad \sum_{h \in H} \chi^{h}=\sum_{h \in H} e^{h}$

(xii) $\quad \sum_{h \in H} \varphi^{h}=0$

(xiii) $\quad\left(\chi^{h}, \varphi^{h}\right) \in B^{h}(p, \pi)=\left\{(\chi, \varphi) \in R^{S^{*} \times L}: p\left(\chi_{0}-e_{0}^{h}\right)+\pi \varphi \leq 0, \quad\right.$ and $\left.\forall s \in S \quad p_{s}\left(\chi_{s}-e_{s}^{h}\right) \leq \sum_{j \in J} \sum_{l \in L} p_{s l} A_{s l}^{j} \varphi_{j}\right\}$

(xiv) $\quad(\chi, \varphi) \in B^{h}(p, \pi) \Rightarrow u^{h}(\chi) \leq u^{h}\left(\chi^{h}\right)$

The GEI ignores all monetary phenomena. Neither money nor credit exists and all transactions take place via a giant clearinghouse, which matches receipts from sales and payments for purchases. Thus, all the repercussions stemming from excess liquidity or their lack thereof are abstracted away from the model.

PROPOSITION 8: Suppose that $\sum_{h \in H} m_{s}^{h}+\sum_{b \in B} e^{b}=0, \forall s \in S^{*}, \kappa=0$, and $\lambda=+\infty$ Moreover, there exists an asset $A^{j}=(1, \ldots, 1)$. Then MECBD and GEI coincide.

COROLLARY 1: If the assumptions of Proposition 8 hold but there does not exist a riskless asset and the long-term credit market is closed, then MECBD and GEI coincide with respect to prices, net asset trades and final consumption.

Finally, so long as the quantity of outside money is positive (i.e., $\sum_{h \in H} m_{s}^{h}+\sum_{b \in B} e^{b}>0$ ) the GEI is obtained as a limiting case of MECBD model without long-term loans. The next corollary formalises this intuition.

COROLLARY 2: Suppose that the assumptions of Proposition 8 hold except that $\sum_{h \in H} m_{s}^{h}+\sum_{b \in B} e^{b}>0$ and that all assets are numeraire

(i.e., $\left.\exists \bar{l} \in L \ni\left(A_{s \bar{l}}^{j}\right)_{s \in S} \neq 0, \forall j \in J,\left(A_{s l}^{j}\right)_{s \in S}=0, \forall \hat{l} \in L \backslash\{\bar{l}\}\right)$ and that $A^{j}{ }^{\prime}$ s are linearly independent. Also, let the long-term credit market be closed. Then as $M^{G} \rightarrow \infty$, the MECB attains 
the GEI prices, net asset trades and final consumption in the limit. ${ }^{55}$ Finally, if I impose the restriction that span $[A]=S$ (i.e., complete markets) the Arrow theorem [3] holds.

\subsection{The optimum quantity of money}

A well-known argument in monetary economics is the optimum quantity of money proposition introduced by Friedman [25]. He argues that efficiency in a monetary economy can be established only if nominal interest rates are equal to zero. In other words, assuming positive real interest rates, optimality is achieved when the growth rate of money supply equals the deflation rate of the economy necessary for zero nominal interest rates. Friedman's argument implies an optimal monetary policy such that inflation should equal the pure rate of time preference of the consumers. ${ }^{56}$

My model implies that the Friedman rule holds only if markets are complete, default is precluded and outside money is zero. Alternatively, if outside money is positive, in view of Corollary 2, efficiency is established in the limit as $M^{G} \rightarrow \infty$. When default occurs in equilibrium then interest rates rise and the corresponding default premium is positive and thus there exists a deadweight loss in the economy. Naturally market incompleteness typically generates inefficient equilibria.

\section{Concluding Remarks}

In this paper, an attempt has been made to provide a rigorous framework for analysing financial instability. A general equilibrium model with incomplete asset markets, money, and default has been built. A commercial banking sector that maximises profits subject to capital requirements and a formal definition of financial fragility are also included. The orderly functioning of markets is established, and thus the existence of equilibrium is shown to be compatible with default and financial fragility. The standard monetary policy propositions are established and monetary and regulatory policy are non-neutral.The possibility of a liquidity trap is demonstrated. A version of the "Diamond and Dybvig" result occurs in equilibrium under certain conditions. Equilibria are constrained inefficient.

Financial instability manifests itself in the continuum and may not precipitate a financial crisis if the appropriate policy measures are adopted. Thus, active regulatory policy, as theorem 2 shows, may be used to improve welfare and alleviate adverse distributional effects of financial instability.

Several extensions can be incorporated into the present model:

- Collateral is of central importance with respect to default. The endogenous determination of the value of collateral during periods of fragility is an important variable in crisis prevention. The size and composition of collateral (e.g., pyramiding or tranching) affects the magnitude of the optimal bankruptcy penalty and capital requirements. Thus, formalisation of collateral requirements is necessary before we can quantify their consequences.

- Restricted access of sectors and investors to capital markets causes welfare redistribution and different degrees of suffering with respect to the severity of consequences of financial fragility. ${ }^{57}$

\footnotetext{
${ }^{55}$ The reason that I require linear independence in numeraire asset matrix is to ensure that net asset trades remain bounded and that the Hart counterexample does not occur. For more see, Geanakoplos and Polemarchakis [26]

${ }^{56}$ For a formal treatment of Friedman's argument see Bewley [7], [8] and for a survey of recent results Woodford [61].

${ }^{57}$ I owe this observation to Glenn Hoggarth.
} 
In other words, small borrowers may not be able to borrow instead from capital markets when there is a bank failure implying that they will be hurt most by a crisis (i.e., not also to financial markets).

- Asymmetric or incomplete information and co-ordination failures and their repercussions for financial fragility are well known (e.g., Morris-Shin [42]). Moral Hazard and adverse selection issues with respect to financial intermediation are crucial for credit evaluation and multiplicity of equilibria (i.e., indeterminacy). So long as appropriate information partitions are introduced, then these issues can be raised in the context of this model. ${ }^{58}$ Moreover, the viability of the rational expectations hypothesis in conjunction with informational content of prices can be addressed within such a framework. Consequently, the impact of asymmetries of information in the real economy can be studied empirically.

- The international aspect of financial crises is arguably a major determinant of systemic risk and contagion. The recent literature on third generation models of twin crises points in this direction. The relationship of exchange rate volatility to default and bank profitability is undoubtedly substantial and thus the international sector should be incorporated in this framework. This can be achieved by combining this model with the international sector of Geanakoplos and Tsomocos [27].

- The long-run effects of the proposed New Basel Accord can be appraised in this framework by extending the model to infinite horizon.

- Policy analysis and empirical considerations of the short-run dynamics are studied in the model by conducting comparative statics. Specific comparative statics experiments when one parameterises the model can provide a background upon which policy decisions can be based and crisis prevention policies can be appraised. In particular, if we extend the horizon of the model then the policy maker observes the equilibrium and the short run dynamics of the economy after various aggregate, sectoral or idiosyncratic shocks. The consequences of various crises can be addressed.

\section{References}

[1] Allen, F. and D. Gale, 1998. 'Optimal Financial Crises,' Journal of Finance, 53:1245-1284.

[2]__ and _, 2000. 'Bubbles and Crashes,' Economic Journal, 460:236-255.

[3] Arrow, K.J., 1953. 'Generalisation des Theories de l'Equilibre Economique General et du Rendement Social au cas du Risque,' Econometrie Paris, CNRS, 81-120.

[4] Balasko, Y. and D. Cass. 1989. 'The Structure of Financial Equilibrium: Exogenous Yields and Unrestricted Participation,' Econometrica, 57:135-162.

[5] Bank for International Settlements, 1998. 'Implications of Structural Change for the Nature of Systemic Risk,' Basel, Switzerland.

[6] Basel Committee on Banking Supervision, 2001. "The New Basel Accord," Bank of International Settlements, Basel, Switzerland.

\footnotetext{
${ }^{58}$ In Dubey, Geanakoplos and Shubik [19], some of these issues have been analysed in a non-monetary model.
} 
[7] Bewley, T. 1980. 'The Optimum Quantity of Money.' In Models of Monetary Economies, ed. J.H Kareken and N. Wallace. Federal Reserve Bank of Minneapolis.

[8] Bewley, T., 1983. 'A Difficulty with the Optimum Quantity of Money,' Econometrica, 51: 14851504.

[9] Blanchard, O. and S. Fisher, 1989. Lectures on Macroeconomics. Cambridge: M.I.T Press.

[10] Blum J. and M. Hellwig, 1995. 'The Macroeconomic Consequences of Capital Adequacy Requirements for banks,' European Economic Review, 39,739-749.

[11] Bryant. J. 1982. 'A Model of Reserves, Bank Runs, and Deposit Insurance,' Journal of Banking and Finance, 4: 335 - 44.

[12] Buiter, W.H., 1999. 'The Fallacy of the Fiscal Theory of the Price Level,' Mimeo, Bank of England.

[13] _, 1998. 'Neutrality, Price Level Indeterminacy, Interest Rate Pegs, and Fiscal Theories of the Price Level,' N.B.E.R.., Working Paper No.6396, February.

[14] Clower, B.W. 1965. 'The Keynesian Counterrevolution: A Theoretical Appraisal.' In The Theory of Interest Rates, ed. F.H. Hahn and F.P.R Brechling Macmillan.

[15] Clower, B. 1967. 'A Reconsideration of the Microeconomic Foundations of Monetary Theory.' Western Economic Journal, 6: 1-8.

[16] Crockett, A., 1997. 'Maintaining Financial Stability in a Global Economy,' in Federal Reserve Bank of Kansas City's Symposium, Jackson Hole, Wyoming, August 28-30.

[17] Deaton, A., 1991. 'Savings and Liquidity Constraints,' Econometrica, 59: 1221-1248.

[18] Debreu, G., 1951. 'The Coefficient of Resource Utilization,' Econometrica, 19:273-292.

[19] Diamond, D. and P. Dybvig, 1983. 'Bank Runs, Deposit Insurance and Liquidity,' Journal of Political Economy, 91: 401 - 19.

[20] Dubey, P. and J. Geanakoplos, 1992. 'The Value of Money in a Finite-Horizon Economy: A Role for Banks,' in P. Dasgupta, D. Gale et al. (eds.), Economic Analysis of Market and Games. Cambridge: M.I.T press.

[21]__ and _ , 1993. 'Monetary Equilibrium with Incomplete Markets,' forthcoming CFDP.

[22] Dubey P., J. Geanakoplos and M. Shubik, 2000. 'Default in a General Equilibrium Model with Incomplete Markets' Cowles Foundation DP 1247, Yale University.

[23] Dubey, P. and M. Shubik, 1978. 'The Non-cooperative Equilibria of a Closed Trading Economy with Market Supply and Bidding Strategies,' Journal of Economics Theory, 17:1-20.

[24] Freixas, X. and J-C. Rochet, 1998. Microeconomics of Banking. Cambridge, Massachusetts: The MIT Press. 
[25] Friedman, M. 1969. The Optimum Quantity of Money and Other Essays. Aldine.

[26] Geanakoplos, J.D. and H.M. Polemarchakis, 1986. 'Existence, Regularity and Constrained Suboptimality of Competitive Allocations when the Asset Market is Incomplete,' In Essays in Honor of K. Arrow, Vol. III, edited by W. Heller, and D. Starret, Cambridge, U.K.: Cambridge University Press.

[27] Geanakoplos, J. and A. Mas-Colell, 1989. 'Real Indeterminacy with Financial Assets,' Journal of Economic Theory, 47:22-38.

[28] Geanakoplos, J.D. and D.P Tsomocos, 2001. 'International Finance in General Equilibrium,' Ricerche Economiche (forthcoming)

[29] Gonzalez-Hermosillo, B., 1999. 'Determinants of Ex-Ante Banking System Distress: A MacroMicro Empirical Exploration of Some Recent Episodes,' I.M.F. Working Paper, Washington D.C.

[30] Grandmont, J. M., 1983. Money and Value. Cambridge: Cambridge University Press.

[31] Grandmont, J.M. and G. Laroque, 1973. 'On Money and Banking,' Review of Economic Studies, 207-236.

[32] Grandmont, J. M. and Y. Younes, 1973. 'On the Efficiency of a Monetary Equilibrium,' Review of Economic Studies, 149-165.

[33] Grandmont, J. M. and Y. Younes, 1972. 'On the Role of Money and the Existence of a Monetary Equilibrium,' Review of Economic Studies, 39: 355-372.

[34] Gurley, J.G., and E.S. Shaw, 1960. Money in a Theory of Finance, Washington, DC:Brookings.

[35] Hahn, F.H., 1965. 'On Some Problems of Proving the Existence of an Equilibrium in a Monetary Economy,' in The Theory of Interest Rates, ed. F.H. Hahn and F.R.P. Brechling , Macmillan.

[36] Hart, O., 1975. 'On the Optimality of Equilibrium when the Market Structure is Incomplete,' Journal of Economic Theory, 11: 418-443.

[37] Hellwig M., 1981. 'A Model of Borrowing and Lending with bankruptcy,' Econometrica, 45, $1879-1905$.

[38] Hicks, J.R., 1946. Value and Capital, $2^{\text {nd }}$ Edition. Oxford: Oxford University Press.

[39] Hool, R.B., 1976, 'Money, Expectations and the Existence of a Temporary Equilibrium,' Review of Economic Studies, 40:439-445.

[40] International Monetary Fund, 1998. 'Chapter IV: Financial Crises: Characteristics and Vulnerability,' World Economic Outlook, Washington D.C.

[41] Kirman, A. P., 1992. 'Whom or What Does the Representative Individual Represent?' Journal of Economic Perspectives, 6, 2: 117-136. 
[42] Kiyotaki, N. and J. Moore, 1997. 'Credit Cycles,' Journal of Political Economy, Vol. 105, No.2:211-248.

[43] Lucas, R.E., 1980. 'Equilibrium in a Pure Currency Economy,' in J.H. Kareken and N. Wallace, eds., Models of Monetary Economies, Minneapolis: Federal Reserve Bank of Minneapolis. , 1990. 'Liquidity and Interest Rates,' Journal of Economic Theory, 50: 237-264.

[45] Lucas, R.E. and N. Stokey, 1987. 'Money and Interest in a Cash in Advance Economy,' Econometrica, SS: $491-514$.

[46] Magill, M., and M. Quinzii, 1996. Theory of Incomplete Markets. Cambridge, Massachusetts: The MIT Press.

[47] Mishkin F.S., 1994. 'Global Financial Instability: Framework, Events, Issues,' Journal of Economic Perspectives, Vol. 13, Number 4, fall 1994, pp. 3-25.

[48] Morris S., and H.Y. Shin, 2000. 'Rethinking Multiple Equilibria in Macroeconomic Modelling,' Cowles Foundation D.P. 1260, Yale University.

[49] Catarineu-Rabell E. and D.P.Tsomocos, 2001. 'Macroeconomic Consequences and Procyclicality of Changes in Capital Requirerments in a General Equilibrium Model,' mimeo, Bank of England.

[50] Radner, R., 1972. 'Existence of Equilibrium Plans, Prices, and Price Expectations in a Sequence of Markets,' Econometrica, 40(2): 289-303.

[51] Shapley, L.S. and M. Shubik, 1977. 'Trading Using One Commodity as a Means of Payment,' Journal of Political Economy, 85(5):937-968.

[52] Shiller, R., 1990. 'The Term Structure of Interest Rates' in Handbook of Monetary Economics, Vol.1, edited by B.M. Friedman and FH. Hahn, North-Holland.

[53] Shubik, M., 1973. 'Commodity Money, Oligopoly, Credit and Bankruptcy in a General Equilibrium Model,' Western Economic Journal, 11: 24-38.

[54] _, 1999. The Theory of Money and Financial Institutions. Cambridge, Massachusetts: The MIT Press.

[55] _ and D.P. Tsomocos, 1992. 'A Strategic Market Game with a Mutual Bank with Fractional Reserves and Redemption in Gold,' Journal of Economics, 55 (2): 123-150.

[56] _ and C. Wilson, 1997. 'The Optimal Bankruptcy Rule in a Trading Economy Using Fiat Money,' Journal of Economics, 37: 337-354.

[57] Tobin, J., 1982. 'The Commercial Banking Firm: A Simple Model,' Scandinavian Journal of Economics 84(4): 495-530.

[58] _, 1963. 'Commercial Banks as Creators of 'Money',' in Banking and monetary Studies, edited by Deane Carson, for the Comptroller of the Currency, US Treasury, Richard D. Irwin, Inc., Homewood, Illinois, 1963. 
[59] Tsomocos, D.P., 2001. 'Monetary and Regulatory Policy Non-neutrality, Constrained Inefficiency and Determinacy,' mimeo, Bank of England.

[60] Tsomocos, D.P., 2001. 'The Microfoundations of Default in General Equilibrium,' mimeo,Bank of England.

[61] Woodford, M., 1998. 'The Optimum Quantity of Money,' in the Handbook of Monetary Economics, edited by B. Friedman and F. Hahn, North-Holland. 


\section{Appendix}

\section{Proof of Quantity Theory of Money Proposition:}

If $\rho>0$ then banks that hold money either they could have deposited it in the interbank market, extend it in the credit market or alternatively invest it in the asset market. Otherwise, they could have reduced their borrowing by $\varepsilon$, increase $\pi_{\mathrm{s}}^{\mathrm{b}}$ and then increase their payoff by $\nabla \Pi_{\mathrm{s}}^{\mathrm{b}}\left(\pi_{\mathrm{s}}^{\mathrm{b}}\right) \cdot \varepsilon>0 .^{59}$ Similarly, households if they are borrowers will spend all of their cash; or else they should not have borrowed since $\sum_{\mathrm{h} \in \mathrm{H}} \mathrm{u}_{\mathrm{b}}^{\mathrm{h}}=1, \forall \mathrm{b} \in \mathrm{B}$. Finally, after adjusting for asset default the proposition obtains. In $s=0$, all unused cash will be preserved and spent in the next period.

\section{Proof of Proposition 1:}

The fact that $r_{s}, \overline{\mathrm{r}} \geq 0$ is proved in step 2 of the Theorem l's proof. If $\overline{\mathrm{r}}<r_{0}$, then any heH would improve by borrowing $\varepsilon$ more on long-term loan than the short-term and thus $\left(\sum_{b \in B} d_{s}^{b}+\sum_{b \in B} m_{s}^{b}\right)>\left(\sum_{h \in H \backslash\{h\}} \mu_{s}^{h}-\varepsilon\right) /\left(1+r_{0}\right)$. So the short-term credit market would not clear, a contradiction. This transaction is feasible since money is perfectly durable.

\section{Proof of Proposition 2:}

If $\rho<\overline{\mathrm{r}}$ or $\rho<r_{s}$ for some $s \in S$ then let any $b \in B$ borrow $\Delta$ more on the interbank market and extend $\Delta$ more on the corresponding credit market. Then, $b$ will realise $(\overline{\mathrm{r}}-\rho) \Delta\left(\left(r_{s}-\rho\right) \Delta\right)$ more profits and improve $\Pi_{\mathrm{s}}^{\mathrm{b}}$, a contradiction.

\section{Proof of Term Structure of Interest Rates Proposition:}

By theorem 1, money has a positive value, i.e. $p$ 's and $r$ 's stay bounded. Thus, in section 3.1, $\Delta\left(9^{h}\right)=0, \forall h \in H$. Otherwise $h$ could have borrowed $\Delta /\left(1+\mathrm{r}_{\mathrm{s}}\right)>0$ more and spend it on commodities and improve his utility by $\nabla \Pi_{s}^{h}\left(x_{s}^{h}\right) \cdot\left(\frac{\Delta}{\left(1+r_{s}\right) p_{s l}}\right)>0$, for some $l \in L$ and $s \in S$.

Finally, $h$ would have used his left over cash $\Delta=\Delta\left(9^{h}\right)$, w.l.o.g. , to defray his loans. Similarly, no $h$ returns more than what he owes. Thus all money in the economy is returned to the commercial banks, after adjusting for bankruptcy and the equality follows.

\section{Proof of Fisher Effect Proposition:}

It follows immediately from the optimisation conditions.

${ }^{59}$ I will be using the following notation hereafter: $\nabla f_{x_{i}}=\frac{\partial f\left(x_{1}, \ldots, x_{n}\right)}{\partial x_{i}}$. 


\section{Proof of Proposition 3:}

Suppose $\theta_{j}<\lambda_{1} \theta_{1}-\left(1+r_{0}\right) \lambda_{2} \theta_{2}$. Then, let a seller of asset $j$ reduce his sale by $\varepsilon$ and borrow $\varepsilon \lambda_{2}$ more. He can use the money obtained from the loan to buy $\varepsilon \lambda_{2}$ more of asset 2 and sell $\varepsilon \lambda_{1}$ more of asset 1.Then $h$ has to deliver $\varepsilon\left(\lambda_{1} A^{1}-\lambda_{2} A^{2}\right)$ less but he also receives $\varepsilon A^{j}$ less. So, his net future deliveries remain unaffected. However, since $\varepsilon \lambda_{1} \theta_{1}-\varepsilon\left(1+r_{0}\right) \lambda_{2} \theta_{2}>\varepsilon \theta_{j}>0$, he can pay back his loan and use his remaining savings to pay back an extra loan that he can use to increase his consumption, a contradiction with optimisation. For the second part of the inequality, suppose $\theta_{j}>\lambda_{l} \theta_{l}$ $\left(1 /\left(1+r_{0}\right)\right) \lambda_{2} \theta_{2}$ and apply the reverse argument.

\section{Proof of Theorem 1:}

Let $M^{*} \equiv M^{G}+\sum_{\mathrm{h} \in \mathrm{H}} \sum_{\mathrm{s} \in \mathrm{S}^{*}} \mathrm{~m}_{\mathrm{s}}^{\mathrm{h}}+\sum_{\mathrm{b} \in \mathrm{B}} \sum_{\mathrm{s} \in \mathrm{S}^{*}} \mathrm{e}_{\mathrm{s}}^{\mathrm{b}}$ be the total quantity of money ever appearing in the economy. For $h \in H, b \in B$ and $\varepsilon>0$ let

$$
\begin{aligned}
& \sum_{\varepsilon}^{\mathrm{h}}=\left\{\left(x^{h}, \bar{\mu}^{h}, \mu^{h}, d^{h}, \bar{d}^{h}, b^{h}, q^{h}, u^{h}, v^{h}\right) \in \mathfrak{R}_{+}^{L S^{*}} \times \mathfrak{R}_{+} \times \mathfrak{R}_{+}^{S^{*}} \times \mathfrak{R}_{+}^{S^{*}} \times \mathfrak{R}_{+} \times \mathfrak{R}_{+}^{L S^{*}+J} \times \mathfrak{R}_{+}^{L S^{*}+J} \times \mathfrak{R}_{+}^{B} \times \mathfrak{R}_{+}^{S^{*}+J+1}:\right. \\
& 0 \leq \mathrm{x}^{\mathrm{h}} \leq 2 \mathrm{~A} 1, \varepsilon \mathrm{m}_{\mathrm{s}}^{\mathrm{h}} \leq \mu_{\mathrm{s}}^{\mathrm{h}} \leq \frac{1}{\varepsilon}, \varepsilon \mathrm{m}_{0}^{\mathrm{h}} \leq \bar{\mu}_{\mathrm{s}}^{\mathrm{h}} \leq \frac{1}{\varepsilon}, 0 \leq \mathrm{d}_{\mathrm{s}}^{\mathrm{h}} \leq \mathrm{M}^{*}, 0 \leq \overline{\mathrm{d}}^{\mathrm{h}} \leq \mathrm{M}^{*}, \\
& \left.\varepsilon \mathrm{m}_{\mathrm{s}}^{\mathrm{h}} \leq \mathrm{b}_{\mathrm{sl}}^{\mathrm{h}}\left(\mathrm{b}_{\mathrm{j}}^{\mathrm{h}}\right) \leq \frac{1}{\varepsilon}, \varepsilon \leq \mathrm{q}_{\mathrm{sl}}^{\mathrm{h}}\left(\mathrm{q}_{\mathrm{j}}^{\mathrm{h}}\right) \leq \frac{1}{\varepsilon}, \varepsilon \mathrm{m}_{0}^{\mathrm{h}} \leq \mathrm{u}^{\mathrm{h}} \leq \frac{1}{\varepsilon}, \varepsilon \leq \mathrm{v}^{\mathrm{h}} \leq 1\right\}
\end{aligned}
$$

and

$$
\begin{aligned}
& \sum_{\varepsilon}^{\mathrm{b}}=\left\{\left(\mu^{b}, d^{b}, \bar{m}^{b}, m_{s}^{b}, b_{j}^{b}, q_{j}^{b}, c_{s}^{b}, v_{s}^{b}, \pi_{s}^{b}\right) \in \mathfrak{R}_{+} \times \Re_{+} \times \Re_{+} \times \Re_{+}^{s^{*}} \times \Re_{+}^{J} \times \Re_{+}^{J} \times \Re_{+}^{s^{*}+J+2} \times \Re_{+}^{s^{*}}:\right. \\
& \varepsilon \mathrm{e}_{0}^{\mathrm{b}} \leq \mu^{\mathrm{b}} \leq \frac{1}{\varepsilon}, 0 \leq \mathrm{d}^{\mathrm{b}} \leq \mathrm{M}^{*}, \varepsilon \mathrm{e}_{0}^{\mathrm{b}} \leq \overline{\mathrm{m}}^{\mathrm{b}} \leq \frac{1}{\varepsilon}, \varepsilon \mathrm{e}_{\mathrm{s}}^{\mathrm{b}} \leq \mathrm{m}_{\mathrm{s}}^{\mathrm{b}} \leq \frac{1}{\varepsilon}, \varepsilon \mathrm{e}_{0}^{\mathrm{b}} \leq \mathrm{b}_{\mathrm{j}}^{\mathrm{b}} \leq \frac{1}{\varepsilon}, \varepsilon \leq \mathrm{q}_{\mathrm{j}}^{\mathrm{b}} \leq \frac{1}{\varepsilon}, \\
& \left.\varepsilon \leq \mathrm{c}_{\mathrm{s}}^{\mathrm{b}} \leq \mathrm{M}^{*}, \varepsilon \leq \mathrm{v}_{\mathrm{s}}^{\mathrm{b}} \leq 1, \varepsilon \mathrm{e}_{\mathrm{s}}^{\mathrm{b}} \leq \pi_{\mathrm{s}}^{\mathrm{b}} \leq \mathrm{M}^{*}\right\}
\end{aligned}
$$

which are both compact and convex.

Let the typical element of $\sum_{\varepsilon}^{\mathrm{h}}\left(\sum_{\varepsilon}^{\mathrm{b}}\right)$ be $\sigma^{h}\left(\sigma^{b}\right) \in \sum_{\varepsilon}^{\mathrm{h}}\left(\sum_{\varepsilon}^{\mathrm{b}}\right)$. Define

$\mathrm{B}_{\varepsilon}^{\mathrm{h}}(\eta)=\mathrm{B}^{\mathrm{h}}(\eta) \cap \sum_{\varepsilon}^{\mathrm{h}}$ and $\mathrm{B}_{\varepsilon}^{\mathrm{b}}(\eta)=\mathrm{B}^{\mathrm{b}}(\eta) \cap \sum_{\varepsilon}^{\mathrm{h}}$. Also let

$\sigma=\left(\sigma^{l}, \ldots, \sigma^{H}, \ldots, \sigma^{B+H}\right) \in \sum_{\varepsilon}=X_{h \in H \cup B} \sum_{\varepsilon}^{\mathrm{h}}$. Define the map

$\Psi_{\varepsilon}: \sum_{\varepsilon} \rightarrow N$, where

$\mathrm{N}=\left\{\eta=\left(\mathrm{p}, \rho, \mathrm{r}_{\mathrm{s}}, \overline{\mathrm{r}}, \theta, \mathrm{R}\right) \in\left(\mathfrak{R}_{++}^{L S^{*}} \times \mathfrak{R}_{++} \times \mathfrak{R}_{++}^{s^{*}} \times \mathfrak{R}_{++} \times \mathfrak{R}_{++}^{J} \times \mathfrak{R}_{+}^{S^{*}+1+J}\right\}\right.$

and $\Psi_{\varepsilon}$ is defined by equation (i)-(ix). In addition define $(\eta, \sigma)$ to be an $\varepsilon$-MECBD if $\eta=\Psi_{\varepsilon}(\sigma)$ and (x), (i.e. (a) $\sigma^{\mathrm{h}} \in \underset{\sigma^{\mathrm{h}} \in \mathrm{B}_{\varepsilon}^{\mathrm{h}}(\eta)}{\operatorname{Arg} \max } \Pi^{\mathrm{h}}\left(x^{h}\left(\sigma^{h}\right)\right)$ and (b) $\left.\sigma^{\mathrm{b}} \in \underset{\sigma^{\mathrm{b}} \in \mathrm{B}_{\varepsilon}^{\mathrm{b}}(\eta)}{\operatorname{Arg} \max } \Pi^{\mathrm{b}}\left(x^{b}\left(\sigma^{b}\right)\right)\right)$. Note also that all

elements of $\Psi_{\varepsilon}(\sigma)=\eta$ are continuous functions of $\sigma$, since in each market some agents are bidding (offering) strictly positive amounts and repayments are bounded away from 0 by the Inactive Market Hypothesis.

Furthermore, define

$G: N \rightrightarrows \underset{\mathrm{h} \in \mathrm{H} \cup \mathrm{B}}{\mathrm{X}} \sum_{\varepsilon}^{\mathrm{h}}=\sum_{\varepsilon}$, where 
$G^{h}=\sigma^{\mathrm{h}} \in \underset{\sigma^{\mathrm{h}} \in \mathrm{B}_{\varepsilon}^{\mathrm{h}}(\eta)}{\operatorname{Arg} \max } \Pi^{\mathrm{h}}\left(x^{h}\left(\sigma^{h}\right)\right)$ and $G=\underset{\mathrm{h} \in \mathrm{H}}{\mathrm{X}} \mathrm{G}^{\mathrm{h}}$.

Finally, let $F=G \circ \Psi: \sum_{\varepsilon} \rightrightarrows \sum_{\varepsilon}, G$ is convex-valued since $\sigma \rightarrow u^{h}\left(x^{h}\left(\sigma^{h}\right)\right)$ is concave. Recall, $\sigma^{h} \rightarrow x^{h}\left(\sigma^{h}\right)$ is linear, and that $\mathrm{B}_{\varepsilon}^{\mathrm{h}}(\eta)$ is convex. Since $\Psi$ is a function, $F=G \circ \Psi$ is also convex valued. Moreover, if $\varepsilon$ is sufficiently small, $G$ is non-empty, since $m_{s}^{h}, e_{s}^{b}>0 \forall h \in H, b \in B$. When $\varepsilon>0, p_{s l}, \theta, r_{s}, r, R>0$, and since $e^{h}, e^{b} \neq 0, \mathrm{~B}_{\varepsilon}^{\mathrm{h}}(\eta)$ for $h \in H \cup B$ is a continuous correspondence. Hence, by the Maximum Theorem, $G$ is compact-valued and upper semicontinuous, and therefore so is $F$. Note that since we have restricted the domain of $\Psi$ to $\sum_{\varepsilon}$ and since for each good and money, some $h \in H \cup B$ has a strictly positive endowment, the restriction $\Psi$ to strictly positive prices, and interest rates strictly greater than -1 is legitimate. The same applies for $R$ 's since an external agent always guarantees a minimum repayment $\varepsilon>0$ by the Inactive Markets Hypothesis. Finally, observe that the total amount of money is bounded above. Commodity prices, $p_{s l} \leq\left(M^{*}+\varepsilon / L \cdot S^{*} /\right) / \varepsilon \leq 2 M^{*} / \varepsilon$ $\forall s l$. Thus, $p_{s l} A_{j}$ is bounded above and so the external agent never delivers more $\frac{\left|\mathrm{L} \cdot \mathrm{S}^{*}\right| \varepsilon^{2} 2 \mathrm{M}^{*}}{2 \mathrm{M}^{*} \cdot \varepsilon} \leq \varepsilon$ units of money. Thus the total amount of money is $M^{*}+\left(/ L \cdot S^{*} /+/ J /\right) \varepsilon \leq 2 M^{*}$.

Step 1: An $\mathcal{\varepsilon}-M E C B D$ exists for any sufficiently small $\varepsilon>0$.

Proof: The map $F$ satisfies all the conditions of the Kakutani fixed point theorem, and therefore admits a fixed point $F(\sigma) \ni \sigma$ which satisfies $(i)-(x)$ for an $\varepsilon$-MECBD.

For every small $\varepsilon>0$, let $\left(\eta(\varepsilon), \sigma_{\varepsilon}\right)$ denote the corresponding $\varepsilon-M E C B D$.

Step 2: At any $\mathcal{E}-M E C B D, r_{s}(\varepsilon), \overline{\mathrm{r}}(\varepsilon), p(\mathcal{E}) \geq 0 \quad \forall s \in S^{*}$.

Proof: By Propositions 1 and 2.

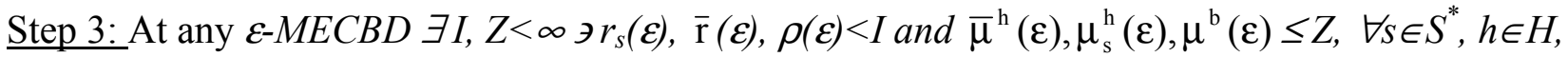
$b \in B$.

Proof: Suppose that $r_{s}(\varepsilon) \rightarrow \infty$. Then $\exists h \in H$ such that $\mu_{\mathrm{s}}^{\mathrm{h}}(\varepsilon) \rightarrow \infty$ and consequently $\mathrm{D}_{\mathrm{sN}(\mathrm{s})}^{\mathrm{h}}=\left(\mu_{\mathrm{s}}^{\mathrm{h}}-\mathrm{M}^{*}\right) \rightarrow \infty$. Then, since $\lambda>>0, \frac{\nabla \pi_{\mathrm{sl}}^{\mathrm{h}}}{\mathrm{p}_{\mathrm{sl}}(\varepsilon)}<<\lambda \mathrm{D}_{\mathrm{sN}(\mathrm{s})}^{\mathrm{h}}$. Thus, $h$ could have been better off by reducing $\mu_{\mathrm{s}}^{\mathrm{h}}(\varepsilon)$ by $\Delta$, a contradiction. Similarly, for $\overline{\mathrm{r}}(\varepsilon), \rho(\varepsilon), \mu_{\mathrm{s}}^{\mathrm{h}}(\varepsilon), \mu^{\mathrm{b}}(\varepsilon)$.

Step 4: For any $\varepsilon-M E C B D, \exists c>0 \ni p_{s l}(\varepsilon)>c, \forall s \in S^{*}, l \in L$.

Proof: Suppose that $p_{s l}(\mathcal{E}) \rightarrow 0$ for some $s \in S^{*}, l \in L$. Then choose $h \in H$. He could have borrowed $\Delta$ more to buy $\Delta p_{s l}(\varepsilon) \rightarrow \infty$. His net gain in utility would be $\left(\frac{\nabla \pi_{\mathrm{sl}}^{\mathrm{h}}}{\mathrm{p}_{\mathrm{sl}}}-\lambda_{\mathrm{sl}}^{\mathrm{h}} \mathrm{r}_{\mathrm{s}}\right) \Delta>0$ since $\lambda_{\mathrm{sl}}^{\mathrm{h}} \mathrm{r}_{\mathrm{s}}<\infty$ and by (A3), $\pi^{h}(0, \ldots, Q, \ldots, 0)>u^{h}(A 1)$ with $Q$ in the $s l$ th place. Thus, $p_{s l} \geq \nabla \Pi_{s l}^{h} / \lambda_{s l}^{h} r_{s}>c>0$.

Step 5: For any $\varepsilon-M E C B D \exists \Gamma \ni \mathrm{q}_{\mathrm{j}}^{\mathrm{h}}(\varepsilon)<\Gamma, \forall j \in J, h \in H \cup B$.

Proof: Suppose that for some $j \in J, \mathrm{q}_{\mathrm{j}}^{\mathrm{h}}(\mathcal{\varepsilon}) \rightarrow \infty$ and $\mathrm{A}_{\mathrm{sl}}^{\mathrm{j}}>0$, for some $l \in L$. Then $h$ can deliver at most $\mathrm{q}_{\mathrm{j}}^{\mathrm{h}} \mathrm{A}_{\mathrm{sl}}^{\mathrm{j}} \leq \max _{\substack{1 \leq 1 \leq \mathrm{L} \\ \mathrm{s} \in \mathrm{S}^{*}}} \sum_{\mathrm{h} \in \mathrm{H}} \mathrm{e}_{\mathrm{sl}}^{\mathrm{h}}=\overline{\mathrm{e}}$, and therefore his disutility from default would be $\left(\lambda_{\mathrm{j}}^{\mathrm{h}} \mathrm{p}_{\mathrm{sl}} \mathrm{q}_{\mathrm{j}}^{\mathrm{h}} \mathrm{A}_{\mathrm{sl}}^{\mathrm{j}}-\mathrm{M}^{*}\right) / p_{s} g_{s}$ $<u(A 1)$. Otherwise, $\sigma^{h}(\varepsilon)$ are not optimal. 
Similarly, suppose that $A_{s, m}^{j}>0$. Again $h$ can deliver at most $q_{j}^{h} A_{S, m} \leq \overline{\mathrm{e}}$ and then his disutility from default would be $\left(q_{j}^{h} A_{S, m}\right) / p_{s} g_{s} \leq u(A 1)$. Otherwise, he would not have optimised.

Step 6: For all $h \in H \cup B, \mathrm{~d}_{\mathrm{s}}^{\mathrm{h}}, \overline{\mathrm{d}}^{\mathrm{h}}, \mathrm{b}_{\mathrm{sl}}^{\mathrm{h}}, \mathrm{b}_{\mathrm{j}}^{\mathrm{h}}, \mathrm{u}^{\mathrm{h}} \leq 2 \mathrm{M}^{*}, \overline{\mathrm{m}}^{\mathrm{b}}, \mathrm{m}_{\mathrm{s}}^{\mathrm{b}}, \mathrm{c}_{\mathrm{s}}^{\mathrm{b}} \leq 2 \mathrm{M}^{*}$ and $/ R /<\mathcal{E}$.

Proof: All variables are constrained by the total amount of money present in the economy and $R$ by assumption.

Step 7: For all $h \in H \cup B, \sigma_{\varepsilon}^{\mathrm{h}}=\underset{\sigma_{\varepsilon}^{\mathrm{h}} \in \mathrm{B}^{\mathrm{h}}(\eta(\varepsilon))}{\arg \max } \pi^{\mathrm{h}}\left(\mathrm{x}^{\mathrm{h}}\left(\sigma^{\mathrm{h}}\right)\right)$, for sufficiently small $\varepsilon>0$.

Proof: From steps 2-6 and the budget constraints $\left(3^{h}\right),\left(8^{h}\right)$ of 3.1 and $\left(1^{h}\right)$ of 3.2 , the $\varepsilon$-constraint is not binding thus concavity of payoffs guarantees the optimality of $\sigma^{h}(\varepsilon)$.

$\operatorname{MECBD}(\eta, \sigma)$ will be constructed by taking the limit of $\varepsilon-M E C B D(\eta(\varepsilon), \sigma(\varepsilon))$, as $\varepsilon \rightarrow 0$. This is achieved by taking limits of sequences of $\varepsilon$ and subsequences of subsequences.

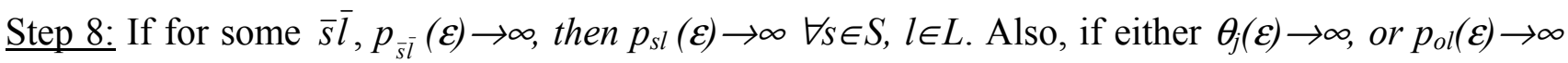
then $p_{s l} \rightarrow \infty, \forall l \in L, s \in S^{*}$.

Proof: Some $h$ owns $e_{\bar{s} l}^{h}>0$. If $p_{s l}(\mathcal{E})$ stays bounded on some subsequence, then by borrowing very large $\bar{\mu}^{\mathrm{h}}$ or $\mu_{0}^{\mathrm{h}}$ if $s=0, h$ can use it to buy $Q$ units of $s l$. Then since $\overline{\mathrm{r}}(\mathcal{\varepsilon}), r_{s}(\mathcal{E})<I$, $h$ can sell $\Delta$ of $\overline{\mathrm{s}} \bar{l}$ acquire $\Delta \mathrm{p}_{\bar{s} \bar{l}}(\varepsilon) \rightarrow \infty$ to defray his loan and improve his utility, a contradiction.

If $\theta_{j}(\varepsilon) \rightarrow \infty$ for some $j \in J$ and $p_{s l}(\varepsilon)<\infty$, let h borrow $\Delta \theta_{j}(\varepsilon) /\left(1+r_{0}(\varepsilon)\right)$ and buy $\Delta q_{j}(\varepsilon) /\left(1+r_{0}(\varepsilon)\right) p_{s l}(\varepsilon)$ of $s l$ and improve his utility. If $\mathrm{p}_{0 \overline{1}}(\varepsilon) \rightarrow \infty$, as previously argued then $p_{o l}(\varepsilon) \rightarrow \infty, \forall l \in L$. Then, by selling $\Delta$ of ol $h$ can acquire $\Delta p_{0 l}(\varepsilon) \rightarrow \infty$. If any of $p_{s l}(\varepsilon) \nrightarrow \infty, \forall \mathrm{s} \in \mathrm{S}$ then by inventorying money he can improve upon his utility.

Step 9: $\exists K>0 \ni p_{s l}(\mathcal{\varepsilon}) / p_{s k}(\mathcal{\varepsilon})<k, \forall l, k \in L, s \in S$.

Proof: Suppose the opposite. Then take $h$ with $\mathrm{e}_{\mathrm{sl}}^{\mathrm{h}}>0$. Let him reduce $\Delta$ his sales of $s l$ and lose $\Delta\left(\Pi^{h}(A 1)-\Pi^{h}(0)\right)$ at most. Then he could buy more $s k$ buy borrowing $\Delta p_{s l}(\varepsilon) /\left(1+r_{s}(\varepsilon)\right)$ and sell $\Delta$ of $s l$. His net gain in utility would be

$\Delta(\varepsilon)\left\{\frac{\mathrm{p}_{\mathrm{sl}}(\varepsilon)}{\left(1+\mathrm{r}_{\mathrm{s}}(\varepsilon) \mathrm{p}_{\mathrm{sk}}(\varepsilon)\right.}\left(\nabla \Pi_{\mathrm{sk}}^{\mathrm{h}}\left(\mathrm{x}^{\mathrm{h}}\right)\right)-(\Pi(\mathrm{A} 1)-\Pi(0)\}>0\right.$

since $p_{s l}(\varepsilon) / p_{s k}(\varepsilon) \rightarrow \infty$ and by step $3, r_{s}(\varepsilon)<I$.

Step 10: $\exists \mathrm{K}^{\prime}>0 \quad \ni p_{o l}(\varepsilon) / p_{s l}(\varepsilon)<\mathrm{K}^{\prime}, \forall s \in S^{*}, l \in L$.

Proof: If $s=0$ then step 9 obtains. Otherwise, set $\Delta\left(4^{h}\right)$ of 3.1 equal to $\Delta p_{s l}(\varepsilon) / 1+r_{s}(\varepsilon)$.

Step 11: $\theta_{\mathrm{j}}(\varepsilon) / \sum \mathrm{p}_{\mathrm{l} \in \mathrm{L}}(\varepsilon) \nrightarrow \infty, \forall j \in J$.

Proof: Suppose the contrary. Let $h$ sell $\frac{\Delta}{(1+\overline{\mathrm{r}}(\varepsilon))}$ of $j$ and borrow $\frac{\Delta \cdot \theta_{\mathrm{j}}(\varepsilon)}{(1+\overline{\mathrm{r}}(\varepsilon))}$ more.

Let him consume $\frac{\Delta \cdot \theta_{j}}{(1+\bar{r}(\varepsilon)) p_{o l}(\varepsilon)}$ more $o l$ for some $l \in L$ in $s=0$. 
Then $h$ can use the proceeds of the asset sale to defray the loan. His net gain of this action will be

$$
\Delta\left(\frac{\theta_{\mathrm{j}}}{\left(1+\overline{\mathrm{r}}(\varepsilon) \mathrm{p}_{\mathrm{ol}}\right.}-\frac{\mathrm{A}_{\mathrm{sl}}^{\mathrm{j}}}{(1+\overline{\mathrm{r}}(\varepsilon)}\right)>0
$$

since $\frac{\theta_{\mathrm{j}}(\varepsilon)}{\mathrm{p}_{01}(\varepsilon)} \rightarrow \infty$

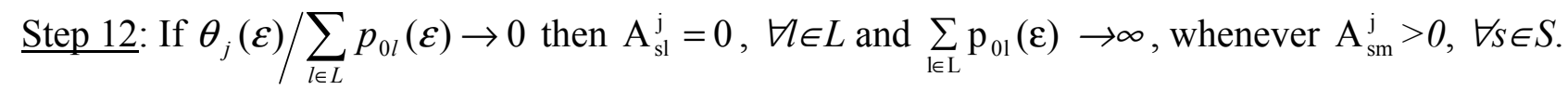

Proof: Suppose $\mathrm{A}_{\mathrm{sl}}^{\mathrm{j}}>0$ for some $s \in S, l \in L$.

Choose $h \in H$ with $\mathrm{e}_{01}^{\mathrm{h}}>0$ for some $l \in L$. Let h sell $\frac{\Delta}{(1+\overline{\mathrm{r}}(\varepsilon))}$ more of $o l$ and increase his loan by $\left(\frac{\Delta}{(1+\overline{\mathrm{r}}(\varepsilon))}\right) p_{0 .}$. Then he could purchase $\frac{\Delta \cdot \mathrm{p}_{01}}{(1+\overline{\mathrm{r}}(\varepsilon))\left(1+\mathrm{r}_{0}(\varepsilon)\right) \theta_{\mathrm{j}}(\varepsilon)}$ of $j$. Then, by borrowing in $s$ and defraying his loan by asset deliveries he can improve his payoff, a contradiction. The same argument applies if $\mathrm{A}_{\mathrm{sm}}^{\mathrm{j}}>0$ and $\sum_{1 \in \mathrm{L}} \mathrm{p}_{01}(\varepsilon) \nrightarrow \infty$.

Step 13: There exists $K \ni p_{s l}(\varepsilon)<K \forall s \in S^{*}, l \in L$.

Proof: Suppose the contrary and w.l.o.g. suppose that $\mathrm{p}_{\overline{\mathrm{s}} \overline{\mathrm{l}}} \rightarrow \infty$ for some $\overline{\mathrm{s}} \in \mathrm{S}^{*}, \overline{\mathrm{l}} \in \mathrm{L}$.

Since $p_{s l}(\varepsilon)=\frac{\sum_{\mathrm{h} \in \mathrm{H}} \mathrm{b}_{\mathrm{sl}}^{\mathrm{h}}(\varepsilon)}{\sum_{\mathrm{h} \in \mathrm{H}} \mathrm{q}_{\mathrm{sl}}^{\mathrm{h}}(\varepsilon)} \leq \frac{\mathrm{M}^{*}}{\sum_{\mathrm{h} \in \mathrm{H}} \mathrm{q}_{\mathrm{sl}}^{\mathrm{h}}(\varepsilon)}$, it must necessarily be $q_{s l}^{h} \underset{\varepsilon \rightarrow 0}{\rightarrow} 0$ for all $s \in S^{*}, l \in L$ by step 8 . At any $\varepsilon$-MECBD, $\bar{r}(\varepsilon), r_{s}(\varepsilon), \rho(\varepsilon)<\delta_{\text {s }}$, by step 3. Hence, at any $\varepsilon-M E C B D$, there are less than $\delta_{s^{-}}$ gains to trade. By continuity, there less than $\delta_{\mathrm{s}^{-}}$gains to trade at $\left(e^{h}\right)_{h \in H}$. However, G-to-T hypothesis guarantees that there are more than $\delta_{s}$-gains to trade $\forall s \in S$, a contradiction.

Step 14: $\eta=\lim _{\varepsilon \rightarrow 0} \eta(\varepsilon)$ and $\lim _{\varepsilon \rightarrow 0}(\eta(\varepsilon), \sigma(\varepsilon))=(\eta, \sigma)$.

Proof:_From the previous steps, $\eta(\mathcal{E})$ is bounded in all components. The same applies for $\sigma(\varepsilon)$. Thus, a convergent susequence can be selected that obtains $(\eta, \sigma)$ in the limit. By continuity of $\Pi^{h}\left(\sigma^{h}\right)$ and $\Pi^{h}\left(\sigma^{b}\right),(\eta, \sigma)$ is a $M E C B D$, and the artificial upper and lower bounds on choices are irrelevant since they are not binding and payoff functions are concave in actions.

\section{Proof of Proposition 4:}

Let $M^{G} \rightarrow \infty$ and consider bounded asset trades. Then by choosing subsequences and further subsequences select a subsequence along which all relative $\sigma$ s and $\eta$ 's converge. By Propsition 8 and its Corollary 2, the limit of the last subsequence coincides with a GEI, a contradiction. Thus, $\left(\sum_{h \in H} q_{j}^{h}+\sum_{b \in B} q_{j}^{b}\right) \rightarrow \infty$. Thus, by feasibility, $M^{G} / \| \theta_{j} / / \rightarrow \infty$ and 
$\left[w_{s}(\eta, \sigma) R_{s} m_{s}^{b}\left(1+r_{s}\right)+w(\eta, \sigma) \bar{R} \bar{m}^{b}(1+\bar{r})+\sum_{j \in J} w_{j}(\eta, \sigma) R_{s j}\left(p_{s l} A^{j}\right)\left(b_{j}^{b} / \theta_{j}\right)\right] \rightarrow \infty, \forall s \in S^{*}, b \in B$.

Finally, by relative boundedness of $\eta^{\prime}$ 's (Theorem 1 , step 14 ), $M^{G} / / / p_{0 l} / / \rightarrow \infty$.

Also, $\exists \overline{\mathrm{Z}} \rightarrow \nabla \Pi_{s}^{b^{*}}\left(\pi_{s}^{b}\right)>\lambda_{s}^{b^{*}}$ for some $b^{*} \in B$, by Shubik-Tsomocos [55]. Similarly, for some $h^{*} \in H$.

Interiority of the maximum on $\pi_{s}^{b}$ and $x_{s}^{h}, \forall s \in S^{*}, b \in B, h \in H$ guarantees bounded aggregate profits and consumptions.

\section{Proof of Proposition 5:}

From step 4 of Theorem $1, p_{s l}>c, \forall s \in S^{*}, l \in L$. Let

$$
\bar{Q}=1+\max \left\{\left\{\frac{\nabla \Pi_{s}^{b}\left(\pi_{s}^{b}\right)}{\nabla \Pi_{\mathrm{s}^{\prime}}^{b}\left(\pi_{\mathrm{s}^{\prime}}^{b}\right)}: s \in S^{*}, b \in B, \pi_{s}^{b} \in \diamond\right\},\left\{\frac{\nabla \Pi_{s}^{h}\left(x_{s}^{h}\right)}{\nabla \Pi_{\mathrm{s}^{\prime}}^{h}\left(x_{\mathrm{s}^{\prime}}^{h}\right)}: s \in S^{*}, h \in H, x_{s}^{h}<A\right\}\right\} .
$$

where $\diamond=\left\{\pi_{\mathrm{s}}^{\mathrm{b}} \in \mathfrak{R}_{+}^{\mathrm{s}+1}: \pi_{\mathrm{s}}^{\mathrm{b}} \leq 1+\max _{0 \leq \mathrm{s} \leq \mathrm{S}} \sum_{\mathrm{b} \in \mathrm{B}} \mathrm{e}_{\mathrm{s}}^{\mathrm{b}}+\max _{0 \leq \mathrm{s} \leq \mathrm{S}} \sum_{\mathrm{h} \in \mathrm{H}} \mathrm{m}_{\mathrm{s}}^{\mathrm{h}}\right\}$.

If some $h$ goes bankrupt then he can reduce his bid on a commodity $l$ by $\varepsilon$ and use this amount to defray his loan. His gain in utility will be $\varepsilon \lambda_{\mathrm{sl}}^{\mathrm{h}}$ whereas his loss will be at most

$$
\frac{\varepsilon \nabla \Pi_{l}^{h}\left(x_{l}^{h}\right)}{p_{l}} \leq \frac{\varepsilon \nabla \Pi_{l}^{h}\left(x_{l}^{h}\right) \bar{Q}}{c}
$$

Thus, if $\lambda^{*}=\frac{\overline{\mathrm{Q}}}{\mathrm{c}} \max \left\{\nabla \Pi_{l}^{h}\left(x_{l}^{h}, h \in H, l \in L, x_{l}^{h} \in \diamond\right\}\right.$ then as long as $\lambda>\lambda^{*}$ no $h$ will go bankrupt.

Conversely, if $\sum_{\mathrm{h} \in \mathrm{H}} \mu_{\mathrm{s}}^{\mathrm{h}}>\sum_{\mathrm{h} \in \mathrm{H}} \mathrm{d}_{\mathrm{s}}^{\mathrm{h}}$ and $\lambda<<\lambda^{*}$, by continuity $\exists \underline{\lambda} \exists \mathrm{D}_{\mathrm{s}}^{\mathrm{h}}>0$ for some $h$.

Now since, $\mathrm{q}_{\mathrm{j}}^{\mathrm{b}}=0, \forall j \in J, b \in B$ for $\underline{\lambda} \exists b \in B \ni \mathrm{D}_{\mathrm{sw}}^{\mathrm{b}}>0$.

\section{Proof of Corollary 1 to Proposition 5:}

Since $u^{b}=u$ and $\lambda_{s}^{b}=\lambda, \forall b \in B$, let $U^{B}=/ B / u^{b}=/ B / u$. Then, $\mathrm{D}_{\mathrm{sw}}^{\mathrm{b}}>0$ implies, $\mathrm{D}_{\mathrm{sw}}^{\mathrm{B}}>0$, for some $s \in S$. Also, because loans exceed deposits $\forall s \in S^{*}, \mathrm{D}_{\mathrm{sw}}^{\mathrm{B}}>0, \forall s \in S^{*}$.

\section{Proof of Corollary 2 to Proposition 5:}

Take $\bar{\lambda}=\bar{\lambda}^{b}=\bar{\lambda}^{h}>\lambda^{*}$ of the proof of proposition 5 and the result follows immediately.

\section{Proof of Theorem 2:}

See Tsomocos[59]. 


\section{Proof of Theorem 3:}

See Tsomocos[59].

\section{Proof of Proposition 6:}

From the definition of a $M E C B D$, if we double w.l.o.g. all nominal variables while we half $\lambda$ 's then by doubling all prices we maintain the same consumptions, with double profits for commercial banks.

\section{Proof of Proposition 7:}

Under the maintained hypotheses, let at the original MECBD agent $h$ buy $\mathrm{x}_{\mathrm{sl}}^{\mathrm{h}}$ and sell $\mathrm{x}_{\mathrm{sl}^{\prime}}^{\mathrm{h}}$. From Theorem 1 , step 4, $p_{s l}>c, \forall s \in S^{*}, l \in L$. Let $\forall h \in H, J^{h}=\left\{\mathrm{s} l=\mathrm{s} \in \mathrm{S}^{*}\right.$ and $\left.l \in \mathrm{L}: \mathrm{b}_{\mathrm{sl}}^{\mathrm{h}}>0\right\}$ and $L^{h}=\left\{\mathrm{s} l=\mathrm{s} \in \mathrm{S}^{*}\right.$ and $\left.1 \in \mathrm{L}: \mathrm{q}_{\mathrm{sl}}^{\mathrm{h}}>0\right\}$. Since $p_{s l}>0, \forall s \in S^{*}, l \in L$ and strategy sets are bounded below by $\mathcal{E}, \exists h, h^{\prime}, \forall s l \ni J^{h} \cap L^{h^{\prime}} \neq \varnothing$ (or equivalently $J^{h^{\prime}} \cap L^{h} \neq \varnothing$ ). Otherwise, all traders would be buying or selling the same commodities and then markets would be lopsided. So, $\exists h, h^{\prime}$ involved in reverse transactions when one considers trade in all commodities. Else, either one trader would violate his budget constraint or be left with unused cash.

Then from his optimisation condition, for any $s \in S^{*}$, and w.l.o.g. assume no bankruptcy,

$$
\frac{\nabla \Pi_{s}^{h}\left(x_{s l}^{h}\right)}{p_{s l}}=\frac{\nabla \Pi_{s}^{h}\left(x_{s l^{\prime}}^{h}\right)}{\mathrm{p}_{s l^{\prime}}}\left(1+r_{s}\right) \text {. }
$$

If $L H S>R H S$ then $h$ should have borrowed $\varepsilon \cdot p_{s l}$ more on the $s^{\text {th }}$ credit market, bought $\varepsilon$ units of $s l$, sold $\left(\varepsilon \cdot p_{s l} / p_{s l}\right)\left(1+r_{s}\right)$ of $s l^{\prime}$ to defray the loan and be better off. Alternatively, if $L H S<R H S$, then $h$ should have spent $\varepsilon \cdot p_{s l}$ less on good $s l$, deposited the money in the intertemporal credit market (or borrowed $\varepsilon \cdot p_{s l}$ less, instead), sold $\left(\varepsilon \cdot p_{s l} / p_{s l}\right)(1+\overline{\mathrm{r}})$ less of $s l^{\prime}$ and ended up better off. Note that this last option was feasible, since by hypothesis the agent carries over cash from 0 to 1 (i.e. $\Delta\left(4^{h}\right)$ of $3.1>0)$.

After the change in monetary policy or the regulator's choices by the term structure of interest rates proposition one interest rate must change. Suppose that $r_{s}$ increases yet all $h$ do not change their consumptions. By indecomposability, since every $h$ is buying, and nothing can be bought unless it is sold, some $h$ is selling as well as buying. Thus, for any pair $s l$ and $s l^{\prime}$ that are bought and sold, respectively, by the same $h, p_{s l} / p_{s l}$ 'should fall. But then $s l$ must have a seller, who buys another good $s n$. So, $p_{s n} / p_{s l}$ must also fall. Continuing in this fashion, a commodity $s a$ will be reached eventually that has already been mentioned, and then $\left(p_{s a} / p_{s b}\right)\left(p_{s b} / p_{s c}\right) \ldots\left(p_{s z} / p_{s a}\right)=1$ should be falling, a contradiction.

Suppose, instead that $\overline{\mathrm{r}}$ increases. If $h \in H$ has borrowed on the intertemporal credit market, then $\forall 0 l$ and $s k, s \in S$ that he buys we must have,

$$
\frac{\nabla \Pi_{\mathrm{s}}^{\mathrm{h}}\left(\mathrm{x}_{01}^{\mathrm{h}}\right)}{\mathrm{p}_{01}}=\frac{\nabla \Pi_{\mathrm{s}}^{\mathrm{h}}\left(\mathrm{x}_{\mathrm{sk}}^{\mathrm{h}}\right)}{\mathrm{p}_{\mathrm{sk}}}(1+\overline{\mathrm{r}}) .
$$

Hence, $p_{0 l} / p_{s k}$ must fall if $h$ maintains his consumption. From indecomposability and the previous argument, if all consumptions and $r$ 's stay the same, then all relative prices at period 0 and $s \in S$ must 
stay the same. Thus, $\forall 0 l$ and $s k, s \in S, p_{0 l} / p_{s k}$ must fall. But for $h^{\prime} \in H$ who carries money from 0 to 1 , let $o n$ and $s j$ be commodities he buys. If $h^{\prime}$ does not alter his consumption, and if $r_{s}$ stays fixed, then $p_{o n} / p_{s j}$ must stay fixed, a contradiction.

Remark: If, under the maintained hypothesis, the MECBD involves bankruptcy then the previous arguments are reinforced because the bankruptcy penalties, if $\lambda$ 's $>>0$, affects $\Pi_{s}^{h \prime}$ s.

\section{Proof of Proposition 8:}

From proposition 3 and Term Structure of Interest Rates Proposition, $r_{s}=0, \forall s \in S^{*}$ and $\bar{r}=0$. Then, from the definition of $M E C B D$ and $G E I$ the Proposition follows immediately.

\section{Proof of Corollary 1 to Proposition 8:}

Again since all $r$ 's are equal to zero and no $h \in H$ can carry forward money via assets, the Proposition follows immediately from the definition of $M E C B D$ and $G E I$.

\section{Proof of Corollary 2 to Proposition 8:}

Asset trades stay bounded. From step 4 of Theorem 1, $\mathrm{p}_{\mathrm{s} 1}>c$. Also, since there does not exist any bankruptcy by hypothesis, a buyer of asset $j$ would be able to consume $\mathrm{A}_{\mathrm{sl}}^{\mathrm{j}} /\left(1+r_{s}\right)$ units more of $l$. Since by the Term Structure of Interest Rates proposition, $r_{s} \rightarrow 0$ and the numeraire asset payoffs are linearly independent by assumption, if for some $\mathrm{h}, \mathrm{q}_{\mathrm{j}}^{\mathrm{h}} \rightarrow \infty$ or $\mathrm{b}_{\mathrm{j}}^{\mathrm{h}} \rightarrow \infty$ as $\mathrm{M}^{\mathrm{G}} \rightarrow \infty$, then $\exists \hat{\mathrm{s}} \in S \ni$

$$
\left|\sum_{j \in J}\left(\frac{b_{j}^{h}}{\theta_{j}} A_{s \bar{l}}^{j}\right) /\left(1+r_{s}\right)-\sum_{j \in J}\left(q_{j}^{h} A_{s \bar{l}}^{j}\right)\right| \rightarrow \infty \text {. }
$$

Thus, $h$, given bounded relative prices, either he could buy the whole economy or bankrupt, a contradiction.

Since, by Theorem 1 all the net trades of the agents, $\left(p_{0 l} / / p_{0 l} / /\right),\left(p_{s l} / / \mid p_{s l} / /\right)$ converge along convergent subsequences $\forall s \in S^{*}$ and by the Term Structure of Interest Rates all $r$ 's $\rightarrow 0$, these limiting trades would constitute a GEI. Finally, note that the ( $\mathrm{G}$ to $\mathrm{T})$ hypothesis is automatically satisfied as long as $M^{G} \rightarrow \infty$. The Arrow theorem of complete markets obtains whenever $A$ is of full column rank and $G E I$ coincides with $G E$. 